NBER WORKING PAPER SERIES

\title{
DISABILITY RISK AND THE VALUE OF DISABILITY INSURANCE
}

\author{
Amitabh Chandra \\ Andrew A. Samwick \\ Working Paper 11605 \\ http://www.nber.org/papers/w11605
}

\author{
NATIONAL BUREAU OF ECONOMIC RESEARCH \\ 1050 Massachusetts Avenue \\ Cambridge, MA 02138 \\ September 2005
}

Amitabh Chandra is an Assistant Professor of Public Policy at the Kennedy School of Government at Harvard University and a Faculty Research Fellow at the NBER. Andrew Samwick is a Professor of Economics and Director of the Nelson A. Rockefeller Center at Dartmouth College and a Research Associate at the NBER. We are grateful to the National Institute on Aging and the Funding First program of the Mary Woodard Lasker Charitable Trust for financial support. We are grateful to Andrew Houtenville for generously providing us with access to CPS data that are not publicly available. We thank David Cutler, Doug Staiger, David Wise, and participants at the NBER conference, "The Decline in Disability," for helpful comments. Any errors are our own. Address correspondence to the authors at Amitabh_Chandra@Harvard.edu and Andrew.Samwick@Dartmouth.edu. The views expressed herein are those of the author(s) and do not necessarily reflect the views of the National Bureau of Economic Research.

(C)2005 by Amitabh Chandra and Andrew A. Samwick. All rights reserved. Short sections of text, not to exceed two paragraphs, may be quoted without explicit permission provided that full credit, including (C) notice, is given to the source. 
Disability Risk and the Value of Disability Insurance

Amitabh Chandra and Andrew A. Samwick

NBER Working Paper No. 11605

September 2005

JEL No. H0, I1, J1

\section{$\underline{\text { ABSTRACT }}$}

We estimate consumers' valuation of disability insurance using a stochastic lifecycle framework in which disability is modeled as permanent, involuntary retirement. We base our probabilities of worklimiting disability on 25 years of data from the Current Population Survey and examine the changes in the disability gradient for different demographic groups over their lifecycle. Our estimates show that a typical consumer would be willing to pay about 5 percent of expected consumption to eliminate the average disability risk faced by current workers. Only about 2 percentage points reflect the impact of disability on expected lifetime earnings; the larger part is attributable to the uncertainty associated with the threat of disablement. We estimate that no more than 20 percent of mean assets accumulated before voluntary retirement are attributable to disability risks measured for any demographic group in our data. Compared to other reductions in expected utility of comparable amounts, such as a reduction in the replacement rate at voluntary retirement or increases in annual income fluctuations, disability risk generates substantially less pre-retirement saving. Because the probability of disablement is small and the average size of the loss - conditional on becoming disabled — is large, disability risk is not effectively insured through precautionary saving.

Amitabh Chandra

79 JFK Street

Kennedy School of Government

Harvard University

Cambridge, MA 02138

and NBER

amitabh_chandra@harvard.edu
Andrew Samwick

6106 Rockefeller Hall

Department of Economics

Dartmouth College

Hanover, NH 03755-3514

and NBER

andrew.samwick@dartmouth.edu 


\section{Introduction}

As successive generations of Americans have access to healthier lifestyles and more advanced medical technologies, we can expect the prevalence of work-limiting disabilities to recede. A decline in disability will have important consequences for the nature of employment at older ages and the optimal design of social insurance programs. In this paper, we take initial steps toward understanding these consequences by measuring the disability decline in the working age population over the past two decades and assessing its implications for welfare and saving. We focus on consumers' valuation of disability insurance — either as income or as an assistive technology—- to protect against the risk of permanent disablement. Because the probability of disablement is small but the loss conditional on the event is large, consumers will find it difficult to selfinsure substantially against the risk of disablement through precautionary saving.

To understand changes in the probability of a work-limiting disability, we examine data from twenty-five years of the Current Population Survey (CPS). We begin by documenting the prevalence of disability in the population as a whole, as well as in subpopulations defined by age, gender, education, race, marital status, census region of residence and metropolitan status of residence. We show that the prevalence of disability has declined substantially for men over the age of 55, for whom the unadjusted declines have ranged from 15 to 25 percent of their levels twenty years ago (corresponding to an absolute decline of about 4 percentage points). Disability rates have been increasing for women, so that by 2004 , disability prevalence was roughly equal for men and women. In the cross-section, the largest disparities occur across educational groups: by age 62, about 17 percent of those without a college education have a work-limiting disability, compared 
to about 5 percent of those with a college education or higher.

We then consider the implications of differences in disability risk for welfare and saving in a stochastic life cycle model of consumption. We model disability as involuntary retirement, focusing on the economic implications of unexpectedly lower income. In this paper, we do not consider the impact of a decline in health status on the quality of life that can be purchased with that income. We show that a typical consumer would be willing to pay about 5 percent of lifetime expected consumption to remove the average risk of disability found in the CPS, and perhaps another 4 percent to remove the highest risks we observe in our data. Our simulations also show that the share of preretirement wealth attributable to the average disability risk (for those who do not become disabled) is about 4 percent. For no demographic group that we identify in our empirical work do the simulations suggest that disability risk would account for more than 20 percent of pre-retirement wealth accumulation. Compared to anticipated drops in income at retirement or annual fluctuations in income that generate similar reductions in expected utility, we note that the risk of disability generates less of a saving response. The reason is that saving is a far less effective hedge against low-probability, high-impact events like disablement.

The remainder of the paper is organized as follows. In Section I, we summarize the data on trends in work-limiting disability over the period from $1980-2004$ in the working age population as a whole, as well as for large demographic subgroups. In Section II, we present graphical analyses based on logistic regressions that decompose the raw data into age-profiles for disability prevalence while controlling for other demographics and year-specific shocks to disability rates. To investigate the implications 
of these patterns for welfare and saving, we develop a stochastic life-cycle model of consumption decisions in Section III. In our model, consumers face three reasons for saving: an anticipated income drop at retirement, persistent uncertainty in their annual incomes, and an annual risk of disability prior to retirement. We model disability as permanent, involuntary retirement. In Section IV, we show that disability risk has a relatively large impact on welfare and a smaller impact on saving compared to the other motives for saving. Section V concludes and discusses directions for future work. In the appendix to this paper, we provide a detailed account of trends in work-limiting disability for different demographic groups.

\section{Data Description}

We use data from the March Current Population Survey (CPS) from 1980-2004 for our analysis. The CPS is a monthly survey of the non-institutionalized population that is conducted by the Bureau of Census for the Bureau of Labor Statistics. In March of each year, the standard CPS survey is supplemented with additional questions on demographic characteristics, income, program participation, employment and health insurance. Additionally, there are questions that allow researchers to identify persons with disabilities that limit work. For example, in the last ten years of our sample, the survey asks:

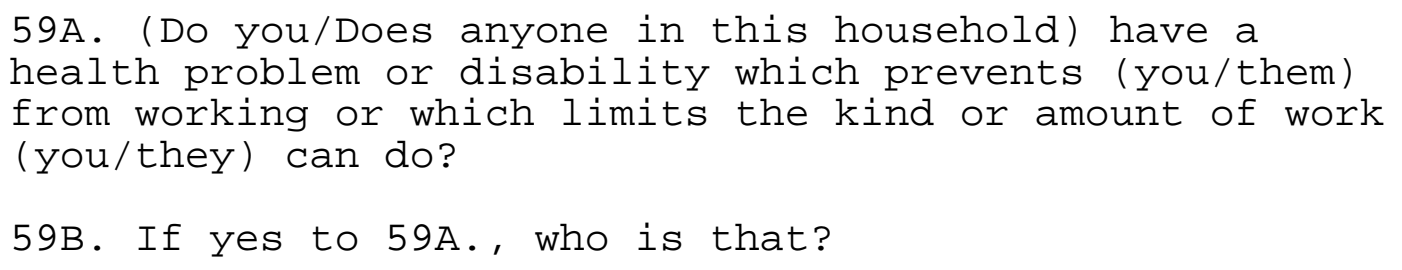


All of the measures of work-limiting disability that we use start with an affirmative answer to this question, because we require a definition of disability that changes little over the period from 1980 to 2004 . Note that a measure of disability based solely on this question does not restrict respondents to be out of the labor force in order to have a work-limiting disability. In fact, it is possible for a respondent to give an affirmative response to the above question, yet also claim to be working. Furthermore, this definition allows a respondent to be working fulltime but in a job other than what they may have chosen in the absence of disability (the question asks for "the kind or amount of work"). Therefore, our estimates of work-limiting disability should not be viewed as providing comprehensive estimates of the phenomenon of disability as defined by ADA legislation (a definition that would include impairments that may not affect an individual's ability to work). ${ }^{1}$ Data from the National Health Interview Survey (NHIS) demonstrate that a large fraction of those with impairments do not report having a worklimiting disability. Many of these respondents are potentially covered by ADA legislation but will not contribute to our measure of work-limiting disability.

While this restriction causes us to undercount a portion of the disabled population, Burkhauser, Houtenville and Wittenburg (2003) demonstrate that some respondents who claim to be work-limited in a single cross-section of the CPS are not permanently worklimited. The authors establish this claim by linking respondents in the CPS in consecutive years and examining the fraction that reported a work limitation in both years. They note that the prevalence of disability as measured by the more stringent two-

\footnotetext{
${ }^{1}$ An impairment is a "disability" under the ADA if it limits a major life activity. Such an activity is not limited to "work-related" spheres. For example, a college professor who loses the ability to drive a car, sit in a chair, or engage in recreational activities as a result of a back injury would generally be classified as being disabled for the purpose of ADA legislation.
} 
year restriction results in lower estimates of disability than those obtained by using a single cross-section.

Burkhauser, et al. also demonstrate that even though different surveys such as the CPS, NHIS and the Survey of Income and Program Participation (SIPP) define disability differently and arrive at different estimates of the level of disability in a given year, each of these surveys generates very similar time trends in disability. This important finding suggests that there have not been substantial changes since 1980 in the prevalence of impairments (or richer measures of work limitations) that might bias our results. For example, the SIPP solicits information on respondents' Activities of Daily Living (ADLs) and Instrumental Activities of Daily Living (IADLs). These broader questions cover a richer range of limitations concerning mobility, paying bills, and doing light housework and hence raise estimates of measured disability. Therefore, the measurement of disability using SIPP data will yield a higher level of disability prevalence, albeit one with the same trend as that computed using data from the CPS or NHIS.

For the purpose of calibrating our model, we need a measure of disability that corresponds to permanent, involuntary retirement. Our strategy is to start with the worklimitation measure and impose additional conditions to ensure that we are measuring withdrawal from the labor force. ${ }^{2}$ An alternative approach to measure permanent

\footnotetext{
${ }^{2}$ Mashaw and Reno (1996) note that there are over 20 definitions of disability in the literature, each being used for a specific purpose. The appropriateness of each definition should be determined by the context in which it is used. Note that our focus on measuring the probability of involuntary retirement is different from quantifying the prevalence of a physical or mental condition. The latter would be of interest if we were trying to understand improvements in (absolute) health status over time. For example, Lakdawalla, Bhattacharya and Goldman (2004) use the NHIS to examine trends in the fraction of people with personal care and routine needs limitations. Their definition of disability deliberately abstracts from the work decision. As the nature of work becomes less physical, the prevalence of a "work limiting disability" will mechanically decline. Lakdawalla, Bhattacharya and Goldman are careful to choose a definition of disability that is robust to this transformation. In contrast to their work, if changes in the nature of work reduce the probability of involuntary retirement through lower disability rates, then it is a channel that
} 
disability might use program participation in the DI or SSI programs. We are reluctant to pursue this approach: as carefully noted by Autor and Duggan (2003), the DI program has been greatly affected by Congressionally mandated changes in the stringency with which DI applicants are screened prior to being classified as bona-fide candidates for the program. Similarly, the decision to apply for DI is influenced by the attractiveness of its economic alternatives (such as unemployment, retirement, or other social programs). Changes in the returns to these alternatives could generate large fluctuations in the measured prevalence of disability. The incentives associated with these alternatives also affect our work-related definition of disability, albeit to a lesser degree because the question that we use does not directly query program participation.

We therefore impose additional criteria to the work-limiting definition of disability to ensure that is closely corresponds to the notion of involuntary retirement. We explore four definitions, where each subsequent definition is more stringent than the previous one:

(1) Respondent has a work-limiting disability.

(2) Respondent has a work-limiting disability and is not presently working.

(3) Respondent has a work-limiting disability, is not presently working, and did not work last year.

(4) Respondent has a work-limiting disability, is not presently working, did not work last year, and is covered by Medicare.

Definition (1) is correlated with the prevalence of involuntary retirement but does not precisely measure it - other research shows that large numbers of respondents who

should be measured. 
claim to have a work-limiting disability are indeed working. ${ }^{3}$ As such, definition (1) should be viewed as providing an upper bound on the phenomenon of involuntary retirement, overstating the impact of disability on both welfare and saving. ${ }^{4}$ Definitions (2) and (3) are undertaken in the spirit of previously discussed work by Burkhauser, Houtenville and Wittenburg (2003), who recommend using a longer time-frame to measure permanent disability. Finally, because SSDI beneficiaries who have been on the program for more than two years are eligible for Medicare benefits, moving from definition (3) to (4) provides us with a lower bound on the prevalence of a work limiting disability. ${ }^{5}$ In our empirical work we focus on definition (3) and use definitions (1) and (4) to inform us of the maximum and minimum disability probabilities. Definitions (2) and (3) yield similar disability prevalence rates, but definition (3) has the advantage of being more conservative. Figure 1 shows the (regression-adjusted) age-disability profile for each of these definitions of disability.

We utilize all observations in the CPS for respondents who were aged 22-64 at the time of the survey. We choose 22 as our lower bound in order to minimize sampling college students while still being able to provide meaningful estimates of work-limiting disability in younger populations. We end our analysis at 64 , since almost all respondents

\footnotetext{
${ }^{3}$ Bound and Burkauser (1999) demonstrate that 65 percent of men who responded positively to the worklimiting disability question on the PSID (in two consecutive years) were working; only 35 percent were not working at all. For women, 52 percent of those who had a work-limiting disability in two consecutive years were working, whereas 48 percent were not working at all.

${ }^{4}$ The Bound and Burkhauser study also notes that 38 percent of disabled men (as identified by two years of work-limiting disability in the PSID) received government transfers, whereas 26 percent of disabled women received such income. These estimates illustrate the wide range of estimates that one obtains by using alternative measures of disability. In future research, we will utilize the HRS dataset, which has been matched to the longitudinal Social Security histories of its respondents. With these data, we will be able to more precisely distinguish between disability and involuntary retirement.

${ }^{5}$ Medicare is a secondary payer for disabled individuals who are also covered through employer provided health insurance. If respondents forget to note this secondary coverage while responding to the CPS questionnaire we would understate the measured prevalence of disability from definition (4). This is another reason for why definition 4 may constitute an absolute lower bound on the prevalence of a worklimiting disability.
} 
claim to be retired after that age. We extract a sample of 2,166,178 respondents in this age range over the 1980 - 2004 time period. For a given year, our sample sizes range from 85,133 in 1980 to over 110,000 since 2002.

In Table 1, we present trends in the prevalence of self-reported disability from 1980-2004. ${ }^{6}$ All tables use our third definition of disability, where the respondent has a work-limiting disability, is not presently working, and did not work last year. We present separate estimates by gender and two broad education categories. We also report a regression estimate of the annual, linear trend in disability. Over these two decades, the prevalence of disability increased by 0.5 percentage points for the population aged 22-64 (with an annual increase of 0.036 percentage points per year). ${ }^{7}$ For men, work-limiting disability increased by 0.7 percentage points, while it increased by 0.4 percentage points for women. Despite starting at different levels in the early 1980s, the gender gap in disability closed by 2004, with women having slightly higher disability rates than men in the most recent period. Disability rates increased for men and women in both education groups. The increase for less educated women and the increase for less educated men were particularly pronounced.

\footnotetext{
${ }^{6}$ Our results are similar to other studies that have utilized a single year of the CPS to measure disability. For example, Burkhauser and Daly (1996) note that in 1990, the prevalence of disability among CPS respondents aged 25-61 was 8.1 percent for men, and 7.8 percent for women. Our sample includes respondents aged 22-64, and the corresponding numbers for men and women are 8.1 and 7.5 percent, respectively. Using a similar question on work-related disability in a single cross section from the SIPP for the same year provided estimates of 11.4 and 11.3, respectively. As noted by Bound and Burkhauser (1999), the higher rates in the SIPP are the likely consequence of explicitly referring to mental health conditions in contributing to work-limiting disability.

${ }^{7}$ Note that an average annual increase of 0.036 percentage points over 25 years would result in a 0.9 percentage point increase in disability. Table 1 demonstrates that the actual change in disability over this period was 0.5 points. The regression line over predicts the increase in disability for this time-interval, because it imposes a linear time-trend on the data; the true trend is disability is best described by a nonlinear time trend. For most of the demographic groups examined in this paper, we found it difficult to reject the linear specification. Therefore, we used this specification throughout the paper.
} 
Table 1 also separates trends in disability prevalence by race/ethnicity and gender and by marital status and gender. The increase in disability for women, noted above, is similar for white and black women, but it is contrasted with a decline for Hispanic women. Disability prevalence increased more for black men than white men, but there was a decline for Hispanic men.

The last panel of Table 1 illustrates the importance of focusing on the prevalence of disability within narrowly defined demographic groups. As noted earlier, there was an increase in the overall prevalence of disability for males. The trends described in this panel note that there was no change in disability for married males. The increase for men is the consequence of substantial increases in disability for never married and widowed, separated or divorced men. Similarly, there has not been a change in disability rates for married women, but there have been larger increases for never married women as well as those who are widowed, separated or divorced.

In interpreting these estimates, it is important to recognize that the reported trends are not necessarily causal — there is nothing in our analysis that suggests that being unmarried raises the probability of having a work-limiting disability. Rather, the fact that a respondent is unmarried at age 55 is better interpreted as being a marker for a particular type of person. Indeed, causality could easily flow in the other direction: it may be the case that because a person is less healthy, he or she is unmarried.

With this caveat in mind, we note that the trends documented in Table 1 (and the next three tables discussed below) are possibly being driven by compositional shifts in the categorization of workers. This interpretation is best understood by re-examining the results of the first panel in Table 1 . Here, we noted an increase in the disability 
prevalence of respondents who did not have a college degree. As the fraction of the population with a college degree increases, the group without a college degree is increasingly representative of individuals who are drawn from the lower tails of the skill and health distributions. Such persons are more likely to have attended worse schools, lived in worse neighborhoods, or been affected by credit constraints that restricted investments in health and human capital. As a result, they also may be more likely to be disabled. This framework suggests that even if there were no changes in the prevalence of disability over time conditional on educational attainment, a growth in the college educated population will manifest itself as increasing disability prevalence for the lesseducated. ${ }^{8}$

Age-specific tabulations in Table 2 demonstrate that the declines in disability have been greatest for the oldest men in our sample. Men are approaching retirement age healthier today than at any point in recent history — the prevalence of work-limiting disability has fallen substantially over the past two decades. In contrast to the declines observed for older populations, there were increases in disability for young and middleaged men. The results for women show a more modest decline in disability rates in the oldest age group and a comparable increase in disability rates for women aged 22-39. In contrast to the results for men, there has been no change in work-limiting disability rates for women aged $40-59 .^{9}$

\footnotetext{
${ }^{8}$ The same compositional shifts are consistent with the increasing disability rates of those with college educations - the subpopulation of college educated now includes less healthier people who formerly would have lacked a college education.

${ }^{9}$ It is instructive to compare our results to those obtained by Lakdawalla, Bhattacharya and Goldman (2004), who use alternative measures of disability reported in the National Health Interview Survey (NHIS). Their measure, unlike ours, measures disability prevalence on an absolute scale (by examining prevalence of ADL and IADL limitations). Using these data for the 1984-1996 period they find no decline in disability rates for those aged 60-69 but note a 0.15 percentage point increase for those respondents aged $18-29$. Using the same data for the $1997-2000$ period, they note a 0.19 percentage point reduction in
} 
When these age patterns are analyzed by educational attainment in the second panel of Table 2, we find that among respondents aged 22-39, there have been large increases in disability for those without a college degree and no change for the college educated. For respondents aged 40-59, changes in disability prevalence are driven by an annual trend of 0.07 percentage points for those without college degrees and an annual trend of 0.02 for those with a college degree. For the oldest group in our analysis, those aged 60-64, the prevalence of disability fell for persons regardless of educational attainment, but it fell more for the college educated.

In Table 3, we disaggregate the trends in disability by age and race in the first panel and by age and marital status in the second. The decline in disability prevalence that was noted for Hispanics is shown to have occurred across all age groups. For blacks, disability rates increased for those below 40 and decreased for those above 60 , with the middle age group showing no significant trend. The estimated disability rate of 29.2 percent for blacks aged 60-64 in 1995-99 is the single highest estimate in our analysis. By marital status, married people have the lowest rates of disability and the most favorable trends over time. All marital status groups had significant increases in disability rates in the lowest age group.

The most important trend in the labor market relevant to disability over this period is the changing nature of work. As the share of jobs in sectors of the economy with high work-related injuries falls (for example, jobs in manufacturing and mining), it is perhaps unsurprising that the prevalence of work-limiting disability declines for older men. As the nature of work changes and fewer jobs require physical strength and dexterity, it is possible that fewer individuals are work-limited. Kutscher and Personick 
(1986) document a decline in manufacturing from 25.1 to 18.5 percent of total employment between 1959 and 1984. Mining fell from 0.9 to 0.6 percent of total employment over the same period of time. At the end of 2004, the Bureau of Labor Statistics (2005) reports that manufacturing represents just 10.8 percent of total employment and that mining represents just 0.4 percent of total employment. Of the manufacturing workers, only 70 percent are classified as production workers.

We further consider this hypothesis by examining the trends in disability prevalence by census region in Table $4 .{ }^{10}$ Across all ages, work-limiting disability grew the most in New England and East South Central states. For all regions, there were significant increases in disability rates for respondents aged 22-39. Among respondents aged $40-59$, the only regions not to see a significant increase in disability rates are those in the East North Central and West North Central. For those aged 60-64, all regions saw declines in disability rates, though the trends in the New England, Middle Atlantic, and East South Central regions were not significant. For this age group, the largest declines in disability are observed in the Mountain region (comprised of Arizona, Colorado, Idaho, Montana, Nevada, New Mexico, Utah and Wyoming); this decline is consistent with an interpretation wherein new cohorts of 60-64 year olds are less likely to have been exposed to work in the mining sector. Similarly, for the "changing nature of work" hypothesis to be true, we should see increases in disability prevalence in regions of the country where manufacturing employment grew in the past twenty years. The East South Central region of the country is one such area (where large Japanese car manufacturers

\footnotetext{
${ }^{10}$ The nine regions are defined as follows-- Mountain: AZ, CO, ID, MT, NV, NM, UT, WY. New England: CT, ME, MA, NH, RI, VT. South Atlantic: DE, DC, FL, GA, MD, NC, SC, VA, WV. West North Central: IA, KS, MN, MO, NE, ND, SD. West South Central: AR, LA, OK, TX. Pacific: AK, CA, HI, OR, WA. East North Central: IL, IN, MI, OH, WI. East South Central: AL, KY, MS, TN. Middle Atlantic: NJ, NY, PA.
} 
located in the mid-1980s). In this region, we observe an increasing trend in the level of disability (of 0.08 percentage points per year), whose magnitude is larger than that of any other region.

While suggestive, this characterization of the data is not without exceptions. First, note that Table 1 demonstrates that there were increases in the levels of worklimiting disability for men with a college degree — a group that was never at risk for working in a coal mine or on the assembly line of a manufacturing plant. Disability prevalence has also grown for college-educated women, another group that is at low risk for job-related injuries. Second, the growth in the prevalence of work limitations for women also poses a problem for an explanation of the decline based on the changing nature of work. At first glance, it might be plausible to explain the increase in female disability as stemming from growing female labor force participation (which grew from 51.6 percent in 1980 to 60.2 percent in 2003). While women of all ages increased their participation between 1980 and 2003, the largest absolute increases in participation occurred for women aged 40-54 (for whom labor force participation grew from 61 percent to almost 75 percent). However, disability trends for this group stayed absolutely constant over the 1980s and 1990s (Table 2, first panel). Finally, we note that the increase in disability in New England states, a group of states that has not witnessed an increase in manufacturing jobs, is comparable to the increase in East Central States. Therefore, no simple explanation is able to reconcile all the facts.

The preceding analysis compares the reported disability rates of respondents of different cohorts at the same age. In results not reported in this paper, we examined changes in the age-disability profile by birth cohort. Because each cohort is observed at 
different points in its lifecycle, we can compare the prevalence of disability at a certain age for a given cohort to that for another cohort at the same age. By examining the agedisability trend across cohorts, we can assess the extent to which different cohorts have the same age-disability profile. In general, we note only small differences across cohorts in disability through the age of 54. These results are supportive of a common age profile across cohorts - disability rises monotonically with age, and the levels appear to be markedly similar at a given age across cohorts. It does not appear to be the case that a certain group of cohorts is systematically more or less disabled than another cohort, an empirical finding that reduces the potential role of "cohort effects" in the data.

We conclude our analysis of the trends in disability prevalence by reporting the extent to which there has been convergence (or divergence) in disability rates across the different demographic groups studied above. These results, which provide a succinct summary of the extent to which the levels of disability across different groups are becoming more or less homogeneous over time, are reported in Table 5 . The table is best explained by an example- Row 1 of the table indicates that the variance in disability rates across the three age categories that we have focused on is estimated to have fallen by 25 percent in 10 years (multiplying the change in variance and its standard error by 2.5 will produce the decline in variance over the 25 year study period). Over the same period, the variance in disability between men and women increased by 8 percent (an estimate not statistically different from zero). Alternatively, in row 8 , we note that the variance in disability across age and gender categories (that is, 3 age categories $\mathrm{x} 2$ gender categories $=6$ age and gender categories) fell by 25 percent. This result implies that disability rates between older and younger men, and older and younger women, are 
becoming more similar. These estimates were calculated by regressing the natural logarithm of the variance in disability, calculated for each year of the data, across these demographic cells on a linear trend. ${ }^{11}$

The table indicates that there has been dramatic convergence in disability rates by age, but divergence across education, marital status, and metropolitan residence groups. There is no statistically significant change in variance across gender, racial groups or by census division. In other words, it is not the case the disability rates for blacks, Hispanics and whites are becoming more similar, or that disability rates across the nine census regions are more uniform. In rows 8 through 18 , we examine convergence in disability rates across more finely defined groupings. We are primarily interested in understanding whether the convergence results noted above for age and gender groups persist in conjunction with the convergence or divergence trends for other variables. Rows 8-13 demonstrate that the convergence in disability rates across age groups persists even when we examine convergence in disability across age and gender groups, age and race groups, age and census division groups, and age and metropolitan status groups. In contrast, there has been no convergence across age and education groups, and there has been divergence across age and marital status categories. The latter result is unsurprising in light of the fact that there was substantial divergence across (univariate) educational and marital status groups - which was partially offset by the convergence across age groups. Rows 14-18 of Table 5 note that there has been divergence in disability rates for groups defined

\footnotetext{
${ }^{11}$ In this regression, the coefficient on the linear trend measures the percent change in variance over time. This interpretation is important to remember, as it implies that the magnitude of the results in Table 5 say nothing about the level of variance at a point in time. We estimate this regression by using all 25 years of the CPS data and computing the variance of disability in each year. We regress the log of this variance on a linear time-trend. We report the coefficient on this trend (multiplied by a factor of 10 to assist in interpretation).
} 
by gender and education, gender and race, and gender and marital status. In other words, the disability rates of black men, white men, black women and white men are diverging are diverging.

\section{Regression Analysis}

The results described in the previous section suffer from an important limitation, in that the demographic composition of the population has been changing over time. For example, the age structure of the population has been changing - a large cohort of babyboomers born in the years after World War II is moving through their lifecycle and affecting the age distribution of the population at each point between 1980 and 2004. Such an effect would contaminate the identification of a declining trend in disability over time, since a secular decline in disability would be partially offset by the increasing age (and consequent disability) of the baby-boomers. In addition, as documented in Section I, there have been changes in education, marital status and the composition of employment. To account for these factors and thus better understand the relationship between age and the prevalence of a work-limiting disability, we follow a regression-based approach where we estimate the following logistic regression model for the probability of being disabled for individual $i$, at age $j$ in year $t\left(\Delta_{\mathrm{ijt}}\right)$ :

(1) $\quad \operatorname{Pr}\left(\Delta_{i j t}=1\right)=F\left(\beta_{0}+\mathbf{X}_{\mathbf{i}}^{\prime} \mathbf{\Theta}+\sum_{j} \gamma_{j}\right.$ Age $e_{j}+\sum_{t} \delta_{t}$ Year $\left._{t}\right)$

In this model, we have included an unrestricted set of age and year dummies, while controlling for factors such as gender, education, race, region of residence, 
metropolitan residence, marital status, and family size and composition. This specification allows for complete nonparametric identification of the age and year effects. In later specifications, we allow for the age effects to vary by different demographic controls by interacting each of the age indicator variables with different values of the control variables.

We begin by reporting the results of our standard specification (where the age effects are constrained to be the same across all demographic groups) in Figure 1. The adjusted age-disability profiles (one for each of the four definitions of work-limiting disability), demonstrate a convex and monotonically increasing relationship in age. The age-disability profile that is the focus of this paper is illustrated with an uninterrupted line. This age-disability profile is what would be observed if secular (i.e., year-specific) changes in disability, as well as in the demographic mix of the CPS sampling frame, were accounted for. The profile starts at approximately 2 percent at the age of 22 and increases to 15 percent at the age of 64 . The profile increases roughly linearly with age until the age of 42 , at which point the relationship becomes increasingly convex. Because of the enormous sample sizes available at our disposal, the profile is very precisely estimated (the standard errors are always less than 0.5 for the estimated profiles, even at older ages). For this reason, in we suppress the confidence intervals in each of the graphs.

While this model is an improvement over examining unadjusted data, it suffers from two potential criticisms. First, the effect of age on disability may vary over time. This is a testable hypothesis, and we explore its empirical content in Figure 2. Here, we modify the logistic regression estimated above by grouping adjacent years and ages so that we can also include year and age interactions. While these interactions are 
statistically significant (and have a marginal F-statistic over 30), the age-disability profile that allows for flexibility over time is seen to be remarkably stable over time. There is a small decline of 1 percentage point in the prevalence of disability of respondents aged 6064 over the sample period, but for ages 22-59, the profiles are stable. As such, the economic significance of the age-disability profile varying over time is negligible. These results provide persuasive evidence that the age-disability profile has remained stable despite one-time events such as the ADA and more than two complete business cycles. Furthermore, they also demonstrate that the trends in disability noted in Tables 1 through 4 are the consequence of changes in the composition of the labor force. When we control for the demographic characteristics of respondents, the increase in disability for younger populations is entirely eliminated.

A second criticism of the model underlying Figure 1 is that it is possible that trends in work-limiting disability are a consequence of "cohort effects." Such effects would represent cohort-specific changes in the disability profile that are not related to age or period effects. For example, if there is a disease (say, the influenza epidemic of 1918) or medical breakthrough that affects some cohorts but not others, such effects will be cohort-specific. As is well known in the economics literature (see, for example, Heckman and Robb (1985)), it is not possible to separate age, period, and cohort effects simultaneously without further assumptions. For example, in Deaton and Paxson (1994), the key identifying assumption is that the year effects sum to zero and are orthogonal to a linear time trend. The Deaton-Paxson assumption is plausible for their study of consumption but is probably inappropriate for the study of disability. 
In our analysis, we assume that cohort effects are zero. Our logic is as follows: there is a powerful biological case for including age effects in our models - disability increases with age because of the onset of illness and muscular-skeletal deterioration that is a consequence of the aging process. In addition, the deleterious effects of disability are often cumulative - although not all disabilities are irreversible, many of the more severe ones probably are. Furthermore, we argue that there is also a case for including year effects in our model. Economy-wide changes in the nature of work (for example, from manufacturing and mining jobs to service jobs) will affect the prevalence of disability. Additionally, legislative interventions such as the ADA will manifest themselves through year effects. Therefore, while there are strong a priori reasons for including age and year effects, the case for cohort effects is less clear on a prima facie basis.

Having established that the age-disability profile is stable over time, we explore trends in prevalence of work-limiting disability by gender in Figure 3. In this figure (and subsequent ones) we allow the age profile to vary by demographic characteristics (here, gender and time.) The graphs adjust for time effects, education attainment, race, marital status, census region of residence, metropolitan residence, and family size and composition. The graphs clearly illustrate the decline in disability for men over the age of 55 in the past twenty years. In contrast, the disability profile for women demonstrates the increase in work-related disability for women aged 35 to 50 . In the unadjusted data reported in Table 1, men and women had similar disability rates in 2004, with women reporting substantially larger increases in disability prevalence between 1980 and 2004 . In contrast, Figure 3 demonstrates that those trends are the consequence of compositional changes; after year effects and other demographic characteristics are controlled for, the 
change in disability profiles for women is not evident. It is interesting to note that these profiles are similar for men and women until the age of 50. After that, the age-disability profile for men accelerates upwards.

We study differences in the age-disability profile by educational attainment in Figure 4 and by racial group in Figure 5. Less educated workers have a higher level of disability at all points in their lifecycle. Additionally, the disability hazard is greater for these workers - at any point in the age distribution, less educated workers have a larger probability of becoming disabled. Therefore, a small difference in the initial level of disablement at the age of 22 is converted to a 10-percentage point difference at the age of 64. For both educational levels, the decline in disability is most pronounced for those over the age of 60 . Figure 5 illustrates disability prevalence profiles by racial group. Despite starting at very similar levels at the age of 22 , the hazard of reporting a worklimiting disability is much greater for Blacks and Hispanics relative to whites (the differences between whites and non-Blacks/non-Hispanics, i.e. those grouped together as "other," are not statistically significant.). On the eve of retirement, the probability of having a disability for whites is approximately 12 percent in 2004 . Yet it is 15 percent for Hispanics and 20 percent for Blacks. In the Appendix figures, we describe age-disability profiles by marital status, gender, gender and education, and metropolitan residence.

To summarize, the prevalence of a work-limiting disability at a typical age of retirement, across all demographic groups and for the average year in our sample, is 15 percent (Figure 1). The lowest prevalence of 6 percent at retirement is observed for college-educated persons in the 2000-2004 period. The highest observed prevalences are 26 percent for never married men (see Appendix Figure A2), and 20 percent for black 
males. These estimates span the range of disablement probabilities and will therefore constitute a central input to our model of intertemporal consumption and saving.

\section{Optimal Consumption in a Stochastic Life-Cycle Model with Disability}

Our empirical work with the CPS documents cross-sectional and time-series differences in disability prevalence. We now seek to quantify the importance of these differences by evaluating their impact on expected utility (welfare) and saving for representative consumers. As a starting point, we develop a stylized model of intertemporal consumption that solves for optimal profiles of consumption while disabled $\left(\mathrm{C}_{\mathrm{s}}{ }^{\mathrm{d}}\right)$ and non-disabled $\left(\mathrm{C}_{\mathrm{s}}{ }^{\mathrm{n}}\right)$. The consumer's value function is defined as:

$$
V_{t}\left(A_{t}, Y_{t}, \Delta_{t}\right) \equiv \max _{\left\{C_{s}^{d}, C_{s}^{n}\right\}} E_{t} \sum_{s=t}^{T} \beta^{s-t}\left(\Delta_{s} u\left(C_{s}^{d}\right)+\left(1-\Delta_{s}\right) u\left(C_{s}^{n}\right)\right)
$$

such that:

a) $u(C)=\frac{C^{1-\gamma}}{1-\gamma}$

b) $A_{s+1}=(1+r(1-\tau))\left(A_{s}+Y_{s}(1-\tau)-C_{s}\right)$

c) $A_{s} \geq 0 \forall s$

d) $\operatorname{Pr}\left(\Delta_{s}=1\right)=\left\{\begin{array}{c}1-\prod_{q=t}^{s}\left(1-\delta_{q}\right), \text { for } \Delta_{\mathrm{t}}=0 \\ 1, \text { for } \Delta_{\mathrm{t}}=1\end{array}\right.$

The value function in each period, $\mathrm{V}_{\mathrm{t}}\left(\mathrm{A}_{\mathrm{t}}, \mathrm{Y}_{\mathrm{t}}, \Delta_{\mathrm{t}}\right)$, has three state variables: the level of assets (A), the level of income (Y), and an indicator for whether the consumer is disabled $(\Delta)$. The value function is equal to the expected discounted utility of consumption in each period from the current period $t$ to the final period $T$, discounted by 
a factor of $\beta$ each period. The rate of time preference is equal to $1 / \beta-1$ and is similar to an interest rate in governing the utility tradeoff across periods. The within-period utility function is assumed to be additively separable in consumption and all other factors that affect utility, including health and leisure, so that these factors can be omitted from the optimization problem. A more detailed model would allow for health and leisure in a given period to affect the willingness of the consumer to spend versus save resources for a later period.

The utility of consumption each period is assumed to take the Constant Relative Risk Aversion (CRRA) form: $\mathrm{u}(\mathrm{C})=\mathrm{C}^{1-\gamma} /(1-\gamma)$, where $\gamma$ is the coefficient of relative risk aversion. With a utility function such as CRRA that has a convex marginal utility function (i.e. u', $(\mathrm{C})>0$ ), there is a precautionary motive for saving, and greater uncertainty in the income process will induce greater saving. ${ }^{12}$

Assets in the next period are equal to the excess of current assets and income over consumption, augmented at the after-tax interest rate (equation 2b). For simplicity, the income tax system is assumed to be linear at a rate, $\tau$, and the portfolio choice is subsumed in the form of a constant interest rate, $r$. Assets are constrained to be nonnegative in each period. The uncertainty in this model comes from two sources. The first is the risk of becoming disabled. The probability that a non-disabled person becomes disabled in period $s$ is $\delta_{\mathrm{s}}$, thereby leading to the expression in (2d) for the probability that a person is disabled in that period. Disability is assumed to be an absorbing state. The second source of uncertainty is the variance in current income while working.

\footnotetext{
${ }^{12}$ The use of the CRRA utility function is standard in both the empirical and theoretical literature on precautionary saving. CRRA utility means that a consumer remains equally willing to engage in gambles over a constant proportion of current wealth as wealth increases. An alternative, and perhaps more realistic assumption, might be that the consumer will accept larger proportional risks as wealth increases. See Kimball (1990) for a discussion and derivation of the key results for precautionary saving.
} 
In the equations below, we state the processes that describe income uncertainty and the evolution of current income:

Before retirement or disability:

a) $\ln \left(Y_{s}\right)=\ln \left(P_{s}\right)+u_{s}$

b) $u_{s+1}=\rho u_{s}+\varepsilon_{s+1}$

c) $\varepsilon_{s} \sim$ i.i.d.N $\left(0, \sigma^{2}\right)$

(3) At retirement or disability:

d) $Y_{s+1}=g Y_{s}$

After retirement or disability:

e) $Y_{s+1}=Y_{s}$

Prior to retirement or disability, the natural log of current income $\left(\mathrm{Y}_{\mathrm{s}}\right)$ is equal to the natural $\log$ of permanent income $\left(\mathrm{P}_{\mathrm{s}}\right)$ plus a shock to income $\left(\mathrm{u}_{\mathrm{s}}\right)$ that follows an $\mathrm{AR}(1)$ process. The innovations to that $\mathrm{AR}(1)$ process are assumed to be independently and identically draws from a normal distribution with mean zero and variance $\sigma^{2} .{ }^{13}$ In the eventuality of either retirement or disablement, income is reduced to a replacement rate $(g)$ of its most recent value. After retirement or disability, income is unchanged at this new level and is no longer uncertain. In the model below, we model life-cycle labor supply as the consumer starting work at age 22 , retiring at age 62 , and living with certainty until age 82 (implying that voluntary retirement is taken in the $40^{\text {th }}$ year out of 60 in the assumed lifetime.)

In this framework, we have included a stylized version of the current Social Security Disability Insurance program. When a worker becomes disabled, she gets the

\footnotetext{
${ }^{13}$ In our simulations, we normalize the mean of the lognormal shock to be one in all periods.
} 
same replacement rate that she would get at retirement, though calculated on income through the year of disability. In both cases, the real value of benefits stays constant over time. More detailed formulations of both the retirement benefit and the disability benefit are possible, though not without substantially increasing the complexity of the model with an additional state variable (e.g., the average index monthly earnings of the worker to date).

The solution method for stochastic optimization problems with multiple state and control variables is discussed in detail in Carroll (2001). The solution begins in the last period of life, $\mathrm{T}$, when the problem is trivial because the household simply consumes all of its assets and after-tax income, yielding optimal values for the control variables, $\mathrm{C}_{\mathrm{T}}{ }^{\mathrm{d}}$ and $\mathrm{C}_{\mathrm{T}}{ }^{\mathrm{n}}$, as a function of the state variables $\mathrm{A}_{\mathrm{T}}$ and $\mathrm{Y}_{\mathrm{T}}$. These solutions generate the value function, $\mathrm{V}_{\mathrm{T}}\left(\mathrm{A}_{\mathrm{T}}, \mathrm{Y}_{\mathrm{T}}, \Delta_{\mathrm{T}}\right)$, and the partial derivative, $\mathrm{V}_{\mathrm{T}}{ }^{\mathrm{A}}\left(\mathrm{A}_{\mathrm{T}}, \mathrm{Y}_{\mathrm{T}}, \Delta_{\mathrm{T}}\right)$, which represents the marginal value of an additional dollar in assets at the beginning of period $\mathrm{T} .{ }^{14}$ Moving back to the period T-1 problem, we can rewrite the objective function as:

$$
V_{T-1}\left(A_{T-1}, Y_{T-1}, \Delta_{T-1}\right) \equiv \max _{\left\{C_{T-1}\right\}}^{\max } u\left(C_{T-1}\right)+\beta E_{T-1}\left[V_{T}\left(A_{T}, Y_{T}, \Delta_{T}\right)\right]
$$

The problem in period $\mathrm{T}-1$ is a special case, since there is no income uncertainty or further risk of disability. More generally, given the function $V_{t+1}\left(A_{t+1}, Y_{t+1}, \Delta_{t+1}\right)$ and the associated partial derivatives, the problem at period $t$ is:

\footnotetext{
${ }^{14}$ The partial derivative, $V_{T}{ }_{T}\left(A_{T}, Y_{T}, \Delta_{T}\right)$, is not needed, since the value of $Y_{T}$ is not influenced by the choice variable in period $\mathrm{T}-1$.
} 


$$
V_{t}\left(A_{t}, Y_{t}, 1\right) \equiv \max _{\left\{C_{t}\right\}} u\left(C_{t}\right)+\beta E_{t}\left[V_{t+1}\left(A_{t+1}, Y_{t+1}, 1\right)\right]
$$

for disabled consumers or

$$
V_{t}\left(A_{t}, Y_{t}, 0\right) \equiv \max _{\left\{C_{t}\right\}}^{\max } u\left(C_{t}\right)+\beta E_{t}\left[\delta_{t+1} V_{t+1}\left(A_{t+1}, Y_{t+1}, 1\right)+\left(1-\delta_{t+1}\right) V_{t+1}\left(A_{t+1}, Y_{t+1}, 0\right)\right]
$$

for non-disabled consumers. These one-period problems have first-order conditions given by:

$$
u^{\prime}\left(C_{t}\right)-\beta(1+r(1-\tau)) E_{t}\left[V_{t+1}^{A}\left(A_{t+1}, Y_{t+1}, 1\right)\right]=0
$$

and

$$
u^{\prime}\left(C_{t}\right)-\beta(1+r(1-\tau)) E_{t}\left[\delta_{t+1} V_{t+1}^{A}\left(A_{t+1}, Y_{t+1}, 1\right)+\left(1-\delta_{t+1}\right) V_{t+1}^{A}\left(A_{t+1}, Y_{t+1}, 0\right)\right]=0
$$

The first term in each first-order condition is the marginal utility of an additional dollar of consumption in period t. The second term is the expected discounted value of saving that dollar to be used in period $t+1$. The dollar grows by the after-tax interest rate and has a marginal value of $\mathrm{V}^{\mathrm{A}}$ at that time, where in the case of a non-disabled consumer $\mathrm{V}^{\mathrm{A}}$ is evaluated at both possibilities for period $\mathrm{t}+1$ - disabled or non-disabled - and weighted appropriately by the probability of disability or its complement. The expected marginal utility of a dollar of assets at time $\mathrm{t}+1$ is discounted back to period $t$ utility at a 
rate $\beta$. The difference between the marginal utility of consumption and the expected marginal utility of assets in the next period is zero at the optimal level of consumption. ${ }^{15}$

Once the optimal consumption rules have been obtained, the models can be simulated forward by specifying initial values of the state variables, drawing random shocks to income and disability status, and applying the consumption rules to generate distributions of asset balances in each period. In our simulations below, we construct average consumption and asset profiles based on 5,000 independent random draws.

The baseline model consists of assumptions about the income process and the preference parameters. We assume a starting value of income at age 22 of $\$ 20,000$ and allow permanent income to grow similarly to the profile for non-college graduates specified in Hubbard, Skinner, and Zeldes (1995). ${ }^{16}$ We also adopt their parameters of $\rho$ $=0.95$ and $\sigma=0.15$ for the $\mathrm{AR}(1)$ income process. We specify a replacement rate of 40 percent at retirement or disability, corresponding to a typical replacement rate from the Social Security system. The constant, pre-tax interest rate, $r$, is assumed to be 5 percent. The tax rate in the linear tax system, $\tau$, is taken to be 20 percent, applied to both labor and investment income. The after-tax interest rate is therefore 4 percent per year. In alternative models, we consider replacement rates of 20 and 60 percent (with an income standard deviation of 15 percent) and income standard deviations of 10 and 20 percent (with a replacement rate of 40 percent).

\footnotetext{
${ }^{15}$ The solution method is complicated by the liquidity constraint. The constraint that $\mathrm{A}_{\mathrm{t}+1}$ cannot be negative implies that the maximum amount of consumption in the prior period is $C_{t}=A_{t}+Y_{t}(1-\tau)$.

${ }^{16}$ We approximate this profile by having real income grow at annual rates of $2.5,1.7,0.5$, and -1.3 percent over the four decades of the working life. Total income growth by the peak (in the $30^{\text {th }}$ year of the working life) is about 55 percent, with a subsequent drop of about 12 percent. The choice of the starting income level is immaterial here, as the entire optimization problem scales linearly with income.
} 
There are two main preference parameters. The coefficient of relative risk aversion, $\gamma$, is assumed to be 3 . In a CRRA model, this results in an intertemporal elasticity of substitution of $1 / 3$. The discount rate, $\beta$, takes one of two values: For simulations of a "patient" consumer, $\beta$ is assumed to be $1 / 1.04$. For simulations of an "impatient" consumer, $\beta$ is assumed to be $1 / 1.08$ percent. In the absence of income uncertainty, an impatient consumer would seek to borrow against future income to finance current consumption, whereas a patient consumer would not. A patient consumer begins saving for retirement early in the lifecycle, while an impatient consumer typically engages in buffer stock saving for several periods before saving for retirement. The difference in behavior results from the comparison of the rate of time preference to the interest rate - the patient consumer has $1 / \beta=1+(1-\tau)$ r, whereas the impatient consumer has $1 / \beta>1+(1-\tau)$ r. The two values chosen are close to the median estimates of the discount rate in Samwick (1998).

The key parameter that we vary in our simulations is the age-disability profile. For all simulations, we adopt the empirical age profile from Figure 1 that reflects the regression-adjusted age profile in our CPS data over the period from 1980 to 2004 . We smooth out the initial disability prevalence at age 22 linearly over all ages, so that the profile starts out at a zero probability of disablement and then rises to the 12 percent prevalence at age 62 that we observe in the data. To consider variation around this baseline, we scale the entire profile up or down proportionally to achieve alternative disability rates at age 62 , including the values of $0,6,12,18$, and 24 percent, with the latter corresponding roughly to the maximum pre-retirement disability rate that we observe for any of our groups empirically. 
Figure 6 shows the impact of disability risk on consumption. Each panel graphs the average level of consumption by age for consumers who do not become disabled under each of four different rates of pre-retirement disability. The top panel is for the impatient consumer, and the bottom panel is for the patient consumer. In each panel, the solid curve indicates the profile that average consumption would take in the absence of a disability risk. Even in this baseline case, it is upward sloping during most of the working life due to the need for precautionary saving against annual income fluctuations in the early years. After the peak, it declines toward the end of the life cycle. There is no important change at retirement in this model, since the voluntary retirement is completely anticipated. The baseline profile is flatter and peaks later for the patient consumer than for the impatient consumer.

As the disability risk increases, the consumption profile starts lower early in life - to allow for more precautionary saving - and remains higher later in life. All of the consumption profiles (in both panels) have the same present value, because the income draws are the same and these are the consumers who do not become disabled before retirement. The distortions in the timing of consumption over the lifecycle induced by the risk of becoming disabled contribute to the welfare loss discussed below. The distortions are larger for the patient consumer than for the impatient consumer, because the former reacts more strongly and sooner to the higher risks of pre-retirement disability.

Figure 7 illustrates the effect of a disabling event on the accumulation of assets. Each panel graphs the average asset values by age for pre-retirement disability risks of 12 and 24 percent. For consumers who do not become disabled before retirement, the asset profiles rise steadily to a peak just prior to retirement, after which they are spent down 
gradually to zero. Consistent with the consumption profiles, the patient consumer consumes less and accumulates more assets prior to retirement. The graphs also show the asset profiles of consumers who become disabled at age 52, after 30 years of work but 10 years prior to voluntary retirement. These profiles track those of those who do not get disabled through that age ${ }^{17}$ and are fairly quickly spent down to zero after disablement. It takes about 15 years for the impatient consumer to exhaust the assets and about 30 years for the patient consumer to do so. After the assets are exhausted, the consumer simply consumes the income provided by the disability insurance program.

Figure 8 shows the range of age-asset profiles corresponding to pre-retirement disability rates up to 24 percent. In each panel, the solid (bottom) profile corresponds to the baseline case with no disability risk. Pre-retirement wealth peaks at $\$ 87,000$ for the impatient consumer and $\$ 147,700$ for the patient consumer, compared to starting income of $\$ 20,000$ and peak average income of about $\$ 32,000$ (at age 52). Successively higher profiles show the effect of increasing the disability risk. With the sample average risk of 12 percent, the peak pre-retirement wealth rises to $\$ 90,100$ (3.6 percent) and 154,000 (4.3 percent) for the impatient and patient consumers, respectively. ${ }^{18}$

\section{Implications for Expected Utility}

Table 6 shows the impact of disability risk on the expected lifetime utility and pre-retirement asset accumulation of the consumer across a range of values for the

\footnotetext{
${ }^{17}$ The graphs should overlap exactly prior to disablement. The disparity is due to the small sample variation in income draws for the subset of random draws that first become disabled at exactly age 52 .

${ }^{18}$ The numbers reported for assets are for the mean profile. Median asset amounts are $15-20$ percent lower on the eve of voluntary retirement. The increase from zero to 12 percent disability risk raises median assets from $\$ 70,200$ to $\$ 73,900$ for the impatient consumer and from $\$ 126,300$ to $\$ 133,300$ for the patient consumer.
} 
replacement rate and income uncertainty. The first panel shows the results for our baseline assumptions of a 40 percent replacement rate at retirement or disability and a 15 percent standard deviation of the shocks to annual income. The next two panels vary the replacement rate to 20 and 60 percent of pre-retirement income, and the last two panels vary the standard deviation of the annual income shock to 20 and 10 percent.

Within each panel, the first column of numbers identifies the probability of becoming disabled prior to the age of anticipated retirement. The numbers range from 6 to 24 percent, with a value of 12 percent corresponding most closely to the average disability prevalence measured in the CPS for those aged 60-64. There are several demographic groups with disability prevalence lower than that average, and the highest value of 24 approximates the highest prevalence estimated in the data (Figure A2 demonstrates that is the prevalence of disability for never married men at age 62). The 6 percent number represents the prevalence of a work-limiting disability at age 62 for college educated workers in 2004 (Figure 4). The estimate of 18 percent is observed for Black men at age 62 (Figure 5). The impact of shifting disability prevalence across time or group - conditional on our choice of baseline parameters - is therefore captured by the simulations shown in the table.

With a CRRA utility function, multiplying consumption in each period (and disability state) by a constant, $k$, multiplies expected utility by a factor of $k^{l-\gamma}$. We can therefore compare consumer welfare across two parameterizations by solving for the value of $k$ such that if consumption in the baseline case is multiplied by $k$, the expected utility would equal the expected utility of the optimal consumption profile under the alternative set of parameters. If $k$ is less (greater) than one, then the consumer is worse 
(better) off under the alternative parameterization. Since we consider the impact of increases in the disability rate, which necessarily make the consumer worse off, we refer to $1-k$ as an equivalent variation, because it measures the amount of money (as a share of lifetime consumption in the baseline case) that a consumer would pay to avoid facing the higher disability risk in the alternative parameterization. The middle two columns show the equivalent variations separately for impatient and patient consumers.

Because consumers have a precautionary motive for saving, increasing disability risk will generate an increase in asset accumulation. As a means of calibrating the equivalent variation, the last two columns of the table show the percentage by which asset accumulation is lower in the baseline case with no disability risk compared to the asset accumulation in the alternative case (for those who do not become disabled) with the specified disability risk. Alternatively, this is the percentage of wealth in the alternative case that is attributable to the non-zero risk of disability.

Increasing the pre-retirement disability risk from zero to the sample average value of 12 percent generates equivalent variations of 4.36 and 5.19 percent for the impatient and patient consumers, respectively. Even though the present value of consumption falls by only 1.92 percent with this disability risk, the consumers would forego about 5 percent of their lifetime consumption to avoid that risk. Recall that disability risk is already partially insured through a stylized DI program in this model—income does not go to zero upon disablement. The 5 percent equivalent variation captures the amount that consumers would be willing to pay to remove the risk that they will ever have to receive payments from that program. The reduction in assets accumulated upon retirement (for 
those who do not become disabled) is about 1.85 percent in the baseline compared to the alternative.

For every 6-percentage point increase in the risk of disability, the present value of pre-retirement consumption falls by about 1 percent, the equivalent variation increases by about 2 percentage points, and the gap in pre-retirement asset accumulation for those who do not become disabled increases by about 2 percentage points. Considering the alternative definitions of disability in Figure 1, the equivalent variation in the strictest definition, corresponding to the additional requirement of being on Medicare and a disability risk at age 62 of 6 percent, is as low as 2.5 percent, with 1 percentage point representing lost consumption. For the least restrictive definition, based solely on the answer to the work-limiting disability question and having a disability risk at age 62 of 18 percent, the equivalent variation is about 7 percent, with 3 percentage points representing lost consumption. Alternatively, the different simulations can correspond to the extremes of our data measured using our baseline definition of disability. College educated workers with only a 6-percent disability risk have equivalent variations of 2.5 percent, while men who never marry have equivalent variations in excess of about 8.5 percent.

The next two panels show the analogous calculations when the replacement rate at retirement or disability is changed by 20 percentage points, to 20 and 60 percent, respectively. Focusing on a pre-retirement disability risk of 12 percent, cutting the replacement rate in half increases the amount of lost consumption by about 35 percent (from 1.92 to 2.60 percentage points), but the equivalent variation more than doubles to about 14 percent of baseline consumption. The asset reduction in the baseline case also 
increases to about 11 percent. With the higher replacement rate of 60 percent, the equivalent variation falls to about 1.4 percent and the asset reduction similarly falls to about 0.7 percent. In all cases, the asset reduction in the baseline due to the absence of disability risk is a bit below the equivalent variation.

The bottom two panels show the calculations when the standard deviation of the annual shock to pre-retirement income is changed by 5 percentage points, to 20 and 10 percent, respectively. The present value of the consumption losses are the same when uncertainty increases (apart from sampling variance) — as the shocks are constrained to have a mean of one. The equivalent variations change very little as income uncertainty changes - the 12 percent disability risk generates an equivalent variation of about $4-5$ percent, again with about a percentage point of difference between impatient and patient consumers. The asset reductions in the baseline case without disability risk are lowest when there is high income uncertainty — the added precautionary saving against annual income fluctuations diminishes the relative importance of precautionary saving against the disability risk.

Table 7 shows the impact on expected utility and pre-retirement asset accumulation of lowering the replacement rate (from 60 to 40 to 20 percent) and increasing the standard deviation of the annual income shock (from 10 to 15 to 20 percent), while holding the pre-retirement disability risk fixed at 0 or 12 percent. In both sets of comparisons, the changes should serve to decrease expected utility and increase asset accumulation. The results in this table can be used to gauge the magnitudes in Table 6. 
With no risk of disability, reductions in the replacement rate affect only the level of income received after retirement. Each reduction of 20 percentage points in the replacement rate lowers the present value of consumption by 2.75 percent. However, the equivalent variations show that neither the impatient nor the patient consumer would be willing to forego that amount of consumption — deducted proportionally in each year- to avoid these reductions. The reason is that the consumers can optimally (rather than merely proportionally) adjust their consumption to offset the lower retirement replacement rate by saving more. The last two columns show that there is a substantial savings response to the reductions in the replacement rate, of 45 and 63 percent for the two increments by the impatient consumer and 28 and 45 percent by the patient consumer. (The proportion is lower for the patient consumer, who is doing more lifecycle saving in the baseline when the replacement rate is 60 percent.)

The loss in the present value of consumption is 3.38 percent for each 20 percentage point reduction in the replacement rate when the disability risk is increased to the sample average of 12 percent. The equivalent variations increase substantially to 4.4 -5.1 percent for the drop to a 40 percent replacement rate and $15.2-15.7$ percent for the drop to a 20 percent replacement rate. Compared to the zero disability risk case, however, the asset reductions in the baseline increase only $2-4$ percentage points for the impatient consumer (to 46.4 and 66.6 percent) and $2-6$ percentage points for the patient consumer (to 30.6 and 50.7 percent).

For changes in the standard deviation of the income shock, the results are comparable for disability risks of zero and 12 percent. In both cases, and for both the impatient and the patient consumer, raising the standard deviation from 10 to 15 percent 
generates an equivalent variation of $9.6-10$ percent and asset reductions in the baseline of $25-30$ percent. An increase in the standard deviation from 10 to 20 percent generates an equivalent variation of about $20-22$ percent and asset reductions in the baseline of 43 -52 percent.

The distinction between the impacts of disability risk, income uncertainty, and the replacement rate on saving and expected utility is summarized in Figure 9. The bottom profile remains the average assets by age for consumers who face a retirement replacement rate of 40 percent, a standard deviation of income shocks of 15 percent, and zero risk of disability. The next lowest profile reflects the impact (on those who do not become disabled) of facing a pre-retirement disability risk of 36 percent, or three times the sample average risk. In calculations analogous to those shown in Table 6, the consumer would be willing to forego about 12 percent of consumption in each period to avoid that risk, and about 12 percent of the wealth accumulated at the pre-retirement peak is attributable to that disability risk.

The top profile in the graphs shows the impact of keeping the disability risk at zero but increasing the standard deviation of the annual income shocks from 15 to 20 percent. The equivalent variation for this shift is about 13 percent, just slightly higher than for the increase in the disability risk to 36 percent. However, about 28 percent of the wealth accumulated at the pre-retirement peak is attributable to the higher income uncertainty, which is more than twice as much as for the profile that increased the disability risk to 36 percent.

The last profile in the graph, with the shortest dashes, shows the impact of keeping the disability risk at zero and the standard deviation of the income shock at 15 
percent, but lowering the replacement rate from 40 to 20 percent. Note that because the disability risk is zero, this reduction affects only the income received after retirement. The peak asset accumulation for this profile is comparable to the peak when income uncertainty is raised to 20 percent. However, the equivalent variation relative to the baseline case is less than 2 percent of lifetime consumption.

What explains these differences? Increases in the disability risk have a large effect on expected utility but a comparatively small effect on asset accumulation. The reason is that saving is less useful in protecting against a low-probability, high-impact risk than the events in the two alternatives. Saving is a perfect response against the certain drop in income at retirement, and because such an ideal response exists, the equivalent variation of reductions to the retirement replacement rate (when there is no disability risk) is quite small. Additional saving is an effective though imperfect hedge against year-to-year income fluctuations. For a change in parameters of a given equivalent variation, the consumer does less saving against annual income risk than against a planned drop in income but more saving than against a risk of disability. Preretirement saving is least attractive as a hedge against a disabling risk.

The age-asset profiles also show that when disability or income risk increases, the impact on saving is immediate. The consequences of disability early in life are critical, but the impact on assets fades over time as the number of years over which the disability could occur is reduced and the income level that would be replaced increases. In contrast, when the replacement rate at planned retirement is lowered, the consumer has forty years to overcome the loss. With an upward sloping income profile over the first thirty years of the working life, the lower replacement rate can be accommodated by 
small reductions in consumption at each age, which accelerate as the date of retirement approaches and income growth slows.

\section{Conclusion}

Using the Current Population Survey over the period from 1980 to 2004, we document the decline in disability over the past two decades, along with cross-sectional differences in the prevalence of disability by gender, education, and other demographic groups. Once we account for compositional changes in demographic characteristics, as well as trends in disability that affect all groups equally, we find that the age-disability profile is fairly stable across time and demographic groups. The exception to this finding is a slight decline in disability prevalence for Americans aged 60-64. These findings suggest that demographic changes and year-specific changes in the disability rate (that affect all groups equally) generate the observed changes in the level of disability over time. In our stochastic lifecycle model of consumption, we estimate that a typical consumer would be willing to pay a premium equal to about 5 percent of lifetime consumption to avoid the average risk of disability found in our data, even in the presence of a stylized disability insurance program that provides the same replacement rate upon disability as at retirement.

Compared to other motives for saving, like an anticipated drop in income at retirement or annual fluctuations in income, disability risk generates little additional saving for a given welfare loss. This is because precautionary saving is less useful as a hedge against low-probability, high-impact events like disability. As a result, it is unlikely that the precautionary saving that occurs specifically due to the empirically 
observed probabilities of disability is large enough to be of macro- or microeconomic importance. We estimate that no more than 20 percent of assets accumulated before voluntary retirement are attributable to disability risks observed in our data. Because the probability of disablement is too small, and the average size of the loss, conditional on becoming disabled is large, disability risk is not effectively insured through precautionary saving. Therefore, the value of disability insurance, whether in the form of income or assistive technology, is likely to be high.

Our paper is silent on the specifics of the optimal disability-insurance system. While the value of such an insurance program may be high, and the typical worker willing to pay for the program, it is important to ensure that its design is actuarially fair by income group. As noted by Bound, Cullen, Nichols, Schmidt (2004), the current DI program permits undesirable transfers from low-income able bodied workers and non-DIeligible disabled persons to comparatively better off DI beneficiaries. These transfers render the program less fair to low-income persons, a group who would have been predicted to be the greatest beneficiaries of this insurance program.

Throughout our analysis, we have defined disability as a health problem or condition that limits the kind or amount of work that a person can do. This definition is focused on the link between disability and work, but work-limiting disabilities as defined in the CPS may include more conditions than those that lead to involuntary retirement. To mitigate this possibility, our main estimates in the paper follow the methodology of Burkhauser, Houtenville and Wittenburg (2003) and require that the respondent not be working at present nor have worked in the prior year. Compared to our baseline estimate of a 5 percent equivalent variation, our lower and upper bounds are 2.5 and 7 percent, 
respectively. Other definitions based on health status, such as the inability to perform certain activities of daily living, would suggest an alternative modeling framework in which the impact of disability would lower the utility from a given amount of consumption in addition to its impact on the ability to work. Developing such a model, in which the savings response could differ markedly from that presented here, is an important topic for further research. 


\section{References}

Autor, David H. and Mark G. Duggan (2003). "The Rise in Disability Rolls and the Decline in Unemployment," Quarterly Journal of Economics, Vol. 118, No. 1, 157-206.

Bound, John and Richard V. Burkhauser (1999). "Economic Analysis of Transfer Programs Targeted on People with Disabilities," in Orley Ashenfelter and David Card (Editors) Handbook of Labor Economics, Volume 3 (Elsevier Science).

Bound, John, Julie Berry Cullen, Austin Nichols, and Lucie Schmidt (2004). "The Welfare Implications of Increasing Disability Insurance Benefit Generosity," Journal of Public Economics, Vol. 88, No. 12, 2487-2514.

Bureau of Labor Statistics (2005). "The Employment Situation: January 2005," (February 4). Available at: http://www.bls.gov/ces/.

Burkhauser, Richard V., and Mary C. Daly (1996). "Employment and Economic WellBeing Following the Onset of a Disability: the role for Public Policy," in Jerry Manshaw, Virginia Reno, Richard Burkhauser and Monroe Berkovitz (Editors.) Disability, Work and Cash Benefits (W.E. Upjohn Institute for Employment Research, Kalamazoo, MI).

Burkhauser, Richard V., Andrew J. Houtenville, and David C. Wittenburg (2003). "A Users Guide to Current Statistics on the Employment of People with Disabilities," in David C. Stapleton and Richard V. Burhauser (eds.) The Decline in Employment of People with Disabilities. Kalamazoo, MI: W.E. Upjohn Institute for Employment Research.

Carroll, Christopher D. (2001). "Lecture Notes on Solution Methods for Microeconomic Dynamic Stochastic Optimization Problems," Manuscript, Johns Hopkins University, April.

Deaton, Angus and Christina H. Paxson (1994). "Intertemporal Choice and Inequality," Journal of Political Economy, Vol. 102, No. 3, 437-467.

Heckman, James J. and Richard Robb (1985). "Alternative Methods for Evaluating the Impact of Interventions," in James Heckman and Burton Singer (eds.) Longitudinal Analysis of Labor Market Data, New York: Cambridge University Press, 156-245.

Hubbard, R. Glenn, Jonathan S. Skinner, and Stephen P. Zeldes (1995). "Precautionary Saving and Social Insurance," Journal of Political Economy, Vol. 103, No. 2, 360-399.

Kimball, Miles S. (1990). "Precautionary Saving in the Small and the Large," Econometrica, Vol. 58, No. 1, 53-73.

Kutscher, Ronald E. and Valerie A. Personick (1986). "Deindustrialization and the Shift to Services," Monthly Labor Review, Vol. 109, No. 6, 3-13. 
Lakdawalla, Darius, Jayanta. Bhattacharya, and Dana. P. Goldman (2004), "Are the Young Becoming More Disabled?” Health Affairs, Vol. 23, No. 1, pp. 168-176.

Mashaw, Jerry L. and Virginia P. Reno (1996). "Balancing Security and Opportunity: the Challenge of Disability Income Policy," Report of the Disability Policy Panel (National Academy of Social Insurance, Washington, DC).

Samwick, Andrew A. (1998). "Discount Rate Heterogeneity and Social Security Reform," Journal of Development Economics, Vol. 57, No. 1, 117-146. 
Table 1: Trends in the Prevalence of Work-Limiting Disability

\begin{tabular}{|c|c|c|c|c|c|c|c|c|c|}
\hline \multicolumn{10}{|c|}{ by Education Level and Gender } \\
\hline & \multicolumn{3}{|c|}{ No College } & \multicolumn{3}{|c|}{ College or more } & \multicolumn{3}{|c|}{ Total } \\
\hline Survey Year & Males & Females & Total & Males & Females & Total & Males & Females & Total \\
\hline $1980-1984$ & 5.9 & 6.0 & 5.9 & 1.2 & 1.5 & 1.3 & 4.7 & 5.2 & 5.0 \\
\hline $1985-1989$ & 5.8 & 5.7 & 5.7 & 1.1 & 1.2 & 1.2 & 4.5 & 4.8 & 4.7 \\
\hline 1990-1994 & 6.0 & 5.8 & 5.9 & 1.1 & 1.1 & 1.1 & 4.7 & 4.8 & 4.7 \\
\hline 1995-1999 & 6.5 & 6.7 & 6.6 & 1.3 & 1.5 & 1.4 & 5.1 & 5.4 & 5.3 \\
\hline $2000-2004$ & 7.0 & 7.1 & 7.0 & 1.4 & 1.7 & 1.6 & 5.4 & 5.6 & 5.5 \\
\hline Annual Trend & 0.060 & 0.068 & 0.065 & 0.017 & 0.020 & 0.019 & 0.040 & 0.032 & 0.036 \\
\hline \multicolumn{10}{|c|}{ by Race and Ethnicity } \\
\hline & \multicolumn{3}{|c|}{ Whites } & \multicolumn{3}{|c|}{ Hispanic } & \multicolumn{3}{|c|}{ Blacks } \\
\hline Survey Year & Males & Females & Total & Males & Females & Total & Males & Females & Total \\
\hline $1980-1984$ & 4.2 & 4.6 & 4.4 & 4.6 & 5.8 & 5.2 & 9.0 & 9.3 & 9.2 \\
\hline 1985-1989 & 3.9 & 4.3 & 4.1 & 5.1 & 5.0 & 5.0 & 8.8 & 7.9 & 8.3 \\
\hline 1990-1994 & 4.1 & 4.2 & 4.2 & 5.2 & 4.9 & 5.0 & 8.8 & 8.1 & 8.4 \\
\hline 1995-1999 & 4.4 & 4.8 & 4.6 & 4.9 & 5.6 & 5.2 & 10.3 & 9.2 & 9.7 \\
\hline $2000-2004$ & 4.9 & 5.1 & 5.0 & 4.3 & 4.9 & 4.6 & 10.3 & 9.3 & 9.8 \\
\hline Annual Trend & 0.041 & 0.032 & 0.037 & -0.029 & -0.021 & -0.025 & 0.087 & 0.027 & 0.054 \\
\hline
\end{tabular}

by Marital Status and Gender

Married

Widowed, Sep. or Div

Never Married

\begin{tabular}{cccccccccc}
\hline Survey Year & Males & Females & Total & Males & Females & Total & Males & Females & Total \\
\hline $1980-1984$ & 4.0 & 3.8 & 3.9 & 8.7 & 10.4 & 9.9 & 5.3 & 5.1 & 5.2 \\
$1985-1989$ & 3.6 & 3.5 & 3.6 & 8.1 & 9.5 & 9.0 & 5.6 & 4.3 & 5.1 \\
$1990-1994$ & 3.6 & 3.4 & 3.5 & 8.6 & 9.5 & 9.2 & 5.6 & 4.5 & 5.2 \\
$1995-1999$ & 3.7 & 3.9 & 3.8 & 9.6 & 10.6 & 10.2 & 6.4 & 5.4 & 6.0 \\
$2000-2004$ & 3.7 & 3.8 & 3.7 & 10.6 & 10.9 & 10.8 & 6.9 & 6.2 & 6.6 \\
& & & & & & & & & \\
Annual Trend & -0.009 & 0.007 & -0.001 & 0.116 & 0.045 & 0.069 & 0.088 & 0.089 & 0.083 \\
\hline \hline
\end{tabular}

Notes:

1)Tables are constructed from CPS data from the 1980-2004 files of Annual Demographic Survey $(n=2,166,178)$. Respondents are aged 22-64 at the time of the survey.

2) Whites refer to non-hispanic whites.

3) Annual trends are calculated as the coefficient on a linear-regression of disability for the relevent demographic group on a linear time-trend.

4) Italicized trends are not different from zero at the 5\% significance level. 
Table 2: Age Specific Trends in the Prevalence of Work-Limiting Disability, by Gender and Education

\begin{tabular}{|c|c|c|c|c|c|c|c|c|c|}
\hline \multirow[b]{3}{*}{ Survey Year } & \multicolumn{9}{|c|}{ by Gender } \\
\hline & \multicolumn{3}{|c|}{ Ages 22-39 } & \multicolumn{3}{|c|}{ Ages 40-59 } & \multicolumn{3}{|c|}{ Ages 60-64 } \\
\hline & Males & Females & Total & Males & Females & Total & Males & Females & Total \\
\hline $1980-1984$ & 1.7 & 1.8 & 1.8 & 6.2 & 7.3 & 6.7 & 18.2 & 17.0 & 17.6 \\
\hline 1985-1989 & 2.0 & 1.7 & 1.9 & 5.8 & 6.6 & 6.2 & 16.4 & 16.1 & 16.2 \\
\hline 1990-1994 & 2.3 & 2.0 & 2.2 & 6.1 & 6.4 & 6.2 & 15.3 & 14.9 & 15.1 \\
\hline 1995-1999 & 2.5 & 2.4 & 2.4 & 6.5 & 7.1 & 6.8 & 16.1 & 16.5 & 16.3 \\
\hline $2000-2004$ & 2.4 & 2.4 & 2.4 & 6.8 & 7.1 & 7.0 & 13.9 & 14.8 & 14.4 \\
\hline Annual Trend & 0.040 & 0.037 & 0.039 & 0.041 & 0.008 & 0.024 & -0.176 & -0.085 & -0.128 \\
\hline
\end{tabular}

\section{by Education}

\begin{tabular}{cccccccccc} 
& \multicolumn{3}{c}{ Ages 22-39 } & \multicolumn{3}{c}{ Ages 40-59 } & \multicolumn{2}{c}{ Ages 60-64 } \\
\hline Survey Year & No College & College & Total & No College & College & Total & No College & College & Total \\
\hline $1980-1984$ & 2.2 & 0.5 & 1.8 & 7.8 & 1.8 & 6.7 & 18.8 & 8.5 & 17.6 \\
$1985-1989$ & 2.4 & 0.5 & 1.9 & 7.5 & 1.6 & 6.2 & 17.9 & 5.9 & 16.2 \\
$1990-1994$ & 2.7 & 0.4 & 2.2 & 7.8 & 1.4 & 6.2 & 16.9 & 5.9 \\
$1995-1999$ & 3.1 & 0.5 & 2.4 & 8.6 & 1.9 & 6.8 & 18.9 & 5.7 & 15.1 \\
$2000-2004$ & 3.2 & 0.5 & 2.4 & 9.0 & 2.1 & 7.0 & 17.2 & 5.4 & 14.4 \\
& & & & & & & & -0.0 \\
Annual Trend & 0.057 & 0.000 & 0.039 & 0.071 & 0.022 & 0.024 & -0.050 & -0.109 & -0.128 \\
\hline \hline
\end{tabular}

Notes:

1)Tables are constructed from CPS data from the 1980-2004 files of Annual Demographic Survey (n=2,166,178). Respondents are aged 2264 at the time of the survey.

2) Whites refer to non-hispanic whites.

3) Italicized trends are not different from zero at the 5\% significance level. 
Table 3: Age Specific Trends in the Prevelence of Work-Limiting Disability, by Race and Marital Status

\section{by Race}

Ages 22-39

Ages 40-59

Ages 60-64

\begin{tabular}{|c|c|c|c|c|c|c|c|c|c|c|c|c|}
\hline Survey Year & Whites & Hispanics & Blacks & Other & Whites & Hispanics & Blacks & Other & Whites & Hispanics & Blacks & Other \\
\hline 1980-1984 & 1.4 & 2.1 & 4.0 & 1.4 & 5.8 & 8.2 & 14.0 & 5.3 & 16.3 & 20.5 & 28.3 & 15.5 \\
\hline 1985-1989 & 1.5 & 2.3 & 3.9 & 1.3 & 5.3 & 7.6 & 12.4 & 5.2 & 14.8 & 18.9 & 27.5 & 13.5 \\
\hline 1990-1994 & 1.8 & 2.3 & 4.1 & 1.9 & 5.3 & 7.9 & 12.1 & 4.9 & 13.5 & 18.8 & 26.6 & 12.5 \\
\hline 1995-1999 & 2.0 & 2.4 & 4.9 & 1.8 & 5.7 & 8.0 & 13.5 & 6.0 & 14.3 & 20.6 & 29.2 & 15.9 \\
\hline 2000-2004 & 2.2 & 1.9 & 4.6 & 1.7 & 6.1 & 7.1 & 13.1 & 5.8 & 12.7 & 17.9 & 25.9 & 11.6 \\
\hline Annual Trend & 0.043 & -0.014 & 0.046 & 0.02 & 0.045 & -0.046 & -0.005 & 0.045 & -0.154 & -0.086 & -0.090 & -0.091 \\
\hline
\end{tabular}

\section{by Marital Status}

\begin{tabular}{|c|c|c|c|c|c|c|c|c|c|c|c|c|}
\hline & & Ages 22-39 & & & Ages 40-59 & & & Ages 60-64 & & & Total & \\
\hline Year & Married & $\begin{array}{c}\text { Widowed,Sep. } \\
\text { or Div. }\end{array}$ & $\begin{array}{c}\text { Never } \\
\text { Married }\end{array}$ & Married & $\begin{array}{c}\text { Widowed,Sep. } \\
\text { or Div. }\end{array}$ & $\begin{array}{c}\text { Never } \\
\text { Married }\end{array}$ & Married & $\begin{array}{c}\text { Widowed,Sep. } \\
\text { or Div. }\end{array}$ & $\begin{array}{c}\text { Never } \\
\text { Married }\end{array}$ & Married & $\begin{array}{c}\text { Widowed,Sep. } \\
\text { or Div. }\end{array}$ & $\begin{array}{c}\text { Never } \\
\text { Married }\end{array}$ \\
\hline 1980-1984 & 0.9 & 3.2 & 3.2 & 5.0 & 12.1 & 15.3 & 14.9 & 25.2 & 22.7 & 3.9 & 9.9 & 5.2 \\
\hline 1985-1989 & 0.9 & 3.1 & 3.4 & 4.5 & 10.7 & 14.1 & 13.5 & 23.6 & 22.8 & 3.6 & 9.0 & 5.1 \\
\hline 1990-1994 & 1.1 & 3.6 & 3.5 & 4.4 & 10.7 & 12.9 & 12.1 & 22.7 & 23.7 & 3.5 & 9.2 & 5.2 \\
\hline 1995-1999 & 1.3 & 4.0 & 3.8 & 4.5 & 11.4 & 14.0 & 12.9 & 24.8 & 25.8 & 3.8 & 10.2 & 6.0 \\
\hline 2000-2004 & 1.2 & 4.2 & 3.6 & 4.5 & 11.6 & 14.6 & 10.6 & 22.9 & 24.4 & 3.7 & 10.8 & 6.6 \\
\hline Annual Trend & 0.021 & 0.066 & 0.027 & -0.021 & 0.009 & 0.003 & -0.183 & -0.070 & 0.090 & -0.001 & 0.069 & 0.083 \\
\hline
\end{tabular}

Notes:

1)Tables are constructed from CPS data from the 1980-2004 files of Annual Demographic Survey (n=2,166,178). Respondents are aged 22-64 at the time of the survey.

2) Whites refer to non-hispanic whites.

3) Annual trends are calculated as the coefficient on a linear-regression of disability for the relevent demographic group on a linear time-trend. 
Table 4: Age Specific Trends in the Prevelence of Work-Limiting Disability, by Census Region

\begin{tabular}{|c|c|c|c|c|c|c|c|c|c|}
\hline & N.Eng & Mid Atl & E.N.Cent & W.N.Cent & S.Atl & E.S.Cent & W.S.Cent & Mount. & Pacific \\
\hline Survey Year & & & & & Ages 22-3 & & & & \\
\hline 1980-1984 & 1.7 & 2.1 & 1.7 & 1.3 & 2.0 & 2.3 & 1.5 & 1.1 & 1.7 \\
\hline 1985-1989 & 1.2 & 2.2 & 2.0 & 1.2 & 1.8 & 2.7 & 2.0 & 1.5 & 1.9 \\
\hline 1990-1994 & 1.7 & 2.1 & 2.2 & 1.5 & 2.3 & 3.8 & 2.2 & 1.8 & 2.0 \\
\hline 1995-1999 & 2.4 & 2.8 & 2.5 & 1.6 & 2.6 & 3.8 & 2.3 & 1.7 & 2.1 \\
\hline 2000-2004 & 2.9 & 3.0 & 2.3 & 1.7 & 2.4 & 3.7 & 2.2 & 1.6 & 2.2 \\
\hline \multirow[t]{2}{*}{ Annual Trend } & 0.075 & 0.049 & 0.036 & 0.028 & 0.033 & 0.084 & 0.036 & 0.024 & 0.026 \\
\hline & & & & & Ages 40-5 & & & & \\
\hline $1980-1984$ & 5.3 & 6.6 & 6.6 & 4.9 & 7.4 & 10.2 & 6.9 & 5.3 & 6.5 \\
\hline 1985-1989 & 4.9 & 6.1 & 6.1 & 4.5 & 7.1 & 9.4 & 6.4 & 5.3 & 5.7 \\
\hline 1990-1994 & 5.0 & 5.7 & 6.0 & 4.3 & 6.6 & 11.2 & 6.9 & 5.2 & 5.8 \\
\hline 1995-1999 & 6.8 & 6.8 & 6.6 & 4.6 & 7.5 & 10.1 & 7.1 & 5.3 & 6.0 \\
\hline 2000-2004 & 6.3 & 7.0 & 6.5 & 4.8 & 7.6 & 10.9 & 7.4 & 5.8 & 6.5 \\
\hline \multirow[t]{2}{*}{ Annual Trend } & 0.078 & 0.031 & 0.008 & 0.003 & 0.021 & 0.037 & 0.037 & 0.025 & 0.014 \\
\hline & & & & & Ages 60-6 & & & & \\
\hline 1980-1984 & 14.5 & 15.9 & 16.5 & 14.9 & 19.9 & 21.3 & 20.1 & 17.5 & 17.6 \\
\hline 1985-1989 & 13.4 & 14.0 & 15.9 & 12.7 & 17.5 & 23.8 & 18.9 & 15.5 & 15.6 \\
\hline 1990-1994 & 13.5 & 13.5 & 14.6 & 11.8 & 16.6 & 19.4 & 17.6 & 14.1 & 14.5 \\
\hline 1995-1999 & 12.7 & 15.0 & 15.4 & 12.3 & 18.2 & 21.6 & 19.4 & 14.8 & 15.6 \\
\hline 2000-2004 & 13.9 & 14.4 & 13.3 & 11.0 & 14.6 & 20.9 & 17.0 & 11.6 & 13.4 \\
\hline \multirow[t]{2}{*}{ Annual Trend } & -0.033 & -0.055 & -0.131 & -0.163 & -0.208 & -0.061 & -0.116 & -0.243 & -0.168 \\
\hline & & & & & All Ages & & & & \\
\hline 1980-1984 & 4.2 & 5.2 & 4.8 & 3.8 & 5.7 & 6.9 & 4.9 & 3.8 & 4.6 \\
\hline 1985-1989 & 3.6 & 4.8 & 4.7 & 3.3 & 5.2 & 7.1 & 4.8 & 3.9 & 4.2 \\
\hline 1990-1994 & 3.9 & 4.5 & 4.7 & 3.4 & 5.1 & 8.0 & 5.1 & 4.0 & 4.3 \\
\hline 1995-1999 & 5.1 & 5.5 & 5.2 & 3.7 & 5.9 & 7.9 & 5.5 & 4.1 & 4.5 \\
\hline 2000-2004 & 5.4 & 5.9 & 5.2 & 3.9 & 5.9 & 8.6 & 5.7 & 4.3 & 4.9 \\
\hline Annual Trend & 0.082 & 0.041 & 0.027 & 0.016 & 0.027 & 0.084 & 0.046 & 0.026 & 0.023 \\
\hline
\end{tabular}

Notes:

1)Tables are constructed from CPS data from the 1980-2004 files of Annual Demographic Survey $(n=2,166,178)$. Respondents are aged 22-64 at the time of the survey.

2) Whites refer to non-hispanic whites

3) Annual trends are calculated as the coefficient on a linear-regression of disability for the relevent demographic group on a linear time-trend.

4) Italicized trends are not different from zero at the 5\% significance level. 
Table 5: Convergence in Disability Prevalence by Demographic Group

\begin{tabular}{lcc}
\hline \hline \multicolumn{1}{c}{ Demographic group } & & \\
& $\begin{array}{c}\text { Percent Change in } \\
\text { Variance every } \mathbf{1 0} \text { Years }\end{array}$ & Standard Error \\
1. Age & & \\
2. Gender & -25 & $(4.0)$ \\
3. Education & 8 & $(32.0)$ \\
4. Race & 46 & $(3.0)$ \\
5. Marital Status & 22 & $(11.0)$ \\
6. Census Division & 85 & $(11.0)$ \\
7. Metropolitan residence & 17 & $(73.0)$ \\
& 177 & $(4.0)$ \\
8. Age and Gender & & $(4.0)$ \\
9. Age and Education & -25 & $(14.0)$ \\
10. Age and Race & -1 & $(12.0)$ \\
11. Age and Marital Status & -69 & $(4.0)$ \\
12. Age and Census Division & 42 & $(4.0)$ \\
13. Age and Metropolitan Status & -25 & $(3.0)$ \\
& -32 & $(10.0)$ \\
14. Gender and Education & & $(11.0)$ \\
15. Gender and Race & 45 & $(15.0)$ \\
16. Gender and Marital Status & 31 & $(29.0)$ \\
17. Gender and Census Division & 80 & \\
18. Gender and Metropolitan Status & 25 & \\
& -25 & \\
\hline \hline
\end{tabular}

1) Table reports the percent change in the variance of disability over time.

2) For each demographic group the table reports the coefficient from a regression of $\ln$ (variance of disability) on a linear time-trend. See text for details.

3 ) There are 3 categories for age, 2 for education, 4 for race, 3 for marital status, 2 for metropolitan residence, and 9 for census division. 
Table 6

Impact of Disability Risk on Expected Utility and Saving

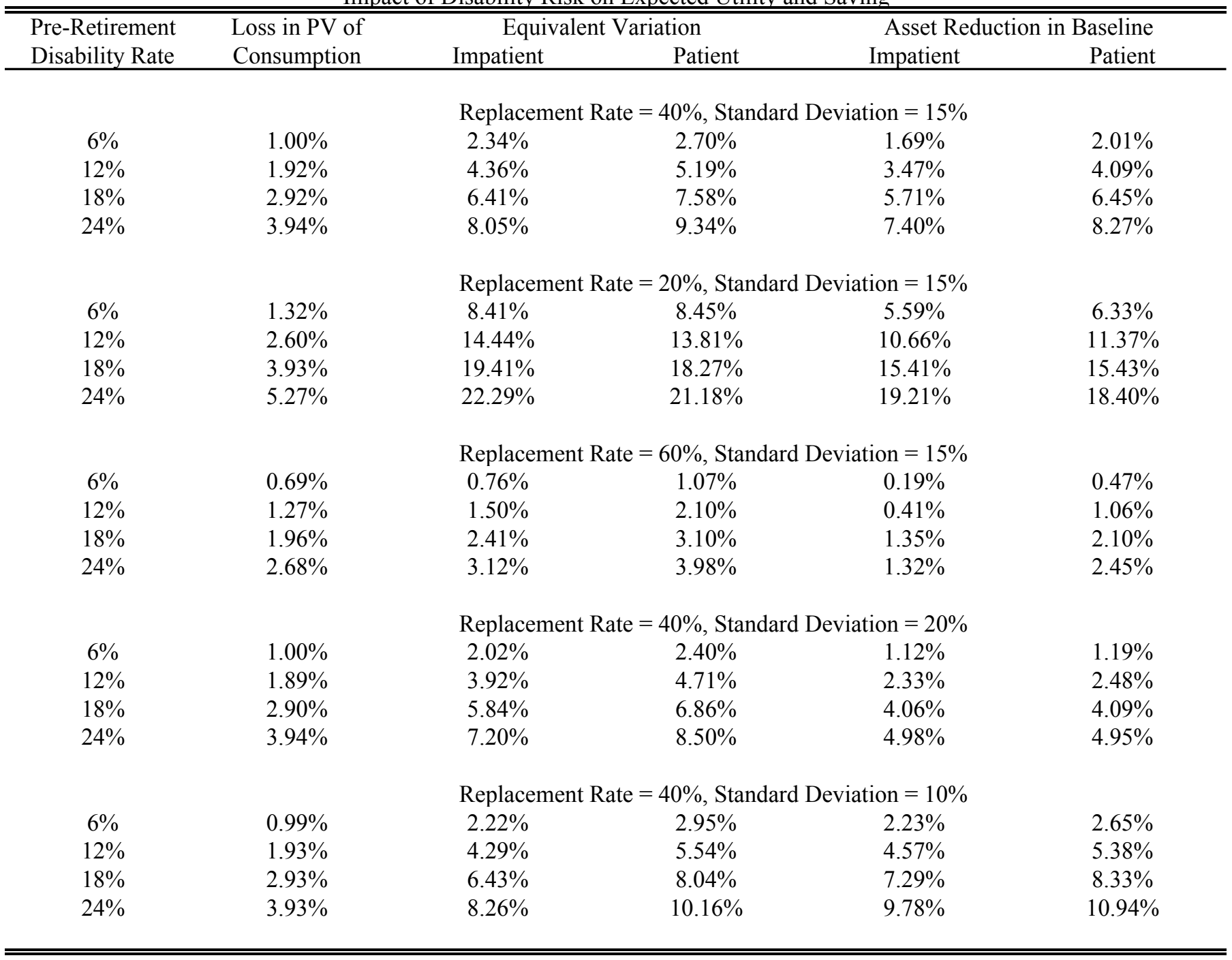

Notes:

1) Pre-Retirement Disability Rate is the prevalence of disability in the last period of the working life (here modeled as 40 working periods and 20 retirement periods).

2) Loss in PV of Consumption is the percent reduction in the present value of expected consumption due to the specified disability risk.

3) Equivalent Variation is the percent reduction in consumption relative to the zero-disability case that would reduce expected utility by the same amount as facing the specified disability risk.

4) Asset Reduction in the Baseline is the percent reduction in asset accumulation in the last period of the working life due to the absence of the specified disability risk.

5) Patient and impatient consumers have rates of time preference equal to 4 and 8 percent, respectively. See the text for a description of the other parameter assumptions. 
Table 7

Impact of Replacement Rate and Income Uncertainty on Expected Utility and Saving

\begin{tabular}{|c|c|c|c|c|c|}
\hline \multirow{2}{*}{$\begin{array}{c}\text { Rep Rate or } \\
\text { Std Deviation }\end{array}$} & \multirow{2}{*}{$\begin{array}{l}\text { Loss in PV of } \\
\text { Consumption }\end{array}$} & \multicolumn{2}{|c|}{ Equivalent Variation } & \multicolumn{2}{|c|}{ Asset Reduction in Baseline } \\
\hline & & Impatient & Patient & Impatient & Patient \\
\hline & \multicolumn{5}{|c|}{ Disability Risk $=0 \%$, Standard Deviation $=15 \%$} \\
\hline $\mathrm{RR}=40 \%$ & $2.75 \%$ & $1.50 \%$ & $2.00 \%$ & $44.69 \%$ & $28.42 \%$ \\
\hline \multirow[t]{2}{*}{$\mathrm{RR}=20 \%$} & $5.50 \%$ & $2.94 \%$ & $3.69 \%$ & $62.77 \%$ & $44.95 \%$ \\
\hline & \multicolumn{5}{|c|}{ Disability Risk $=12 \%$, Standard Deviation $=15 \%$} \\
\hline $\mathrm{RR}=40 \%$ & $3.38 \%$ & $4.36 \%$ & $5.09 \%$ & $46.39 \%$ & $30.62 \%$ \\
\hline \multirow[t]{2}{*}{$\mathrm{RR}=20 \%$} & $6.77 \%$ & $15.69 \%$ & $15.21 \%$ & $66.60 \%$ & $50.69 \%$ \\
\hline & \multicolumn{5}{|c|}{ Disability Risk $=0 \%$, Replacement Rate $=40 \%$} \\
\hline $\mathrm{SD}=15 \%$ & $0.00 \%$ & $9.81 \%$ & $9.98 \%$ & $30.39 \%$ & $26.16 \%$ \\
\hline \multirow[t]{2}{*}{$\mathrm{SD}=20 \%$} & $0.00 \%$ & $22.18 \%$ & $20.92 \%$ & $51.68 \%$ & $44.89 \%$ \\
\hline & \multicolumn{5}{|c|}{ Disability Risk $=12 \%$, Replacement Rate $=40 \%$} \\
\hline $\mathrm{SD}=15 \%$ & $-0.02 \%$ & $9.87 \%$ & $9.64 \%$ & $29.59 \%$ & $25.16 \%$ \\
\hline $\mathrm{SD}=20 \%$ & $-0.04 \%$ & $21.88 \%$ & $20.22 \%$ & $50.54 \%$ & $43.20 \%$ \\
\hline
\end{tabular}

Notes:

1) Disability Risk is the prevalence of disability in the last period of the working life (here modeled as 40 working periods and 20 retirement periods).

2) Comparisons in each panel are made relative to the highest replacement rate $(60 \%)$ and the lowest income uncertainty $(10 \%)$.

3) Loss in PV of Consumption is the percent reduction in the present value of expected consumption due to the specified change in replacement rate or income uncertainty.

4) Equivalent Variation is the percent reduction in consumption relative to the lowest-saving case that would reduce expected utility by the same amount as facing the lower replacement rate or higher income uncertainty.

5) Asset Reduction in the Baseline is the percent reduction in asset accumulation in the last period of the working life due to the absence of the specified reduction in the replacement rate or increase in income uncertainty.

6) Patient and impatient consumers have rates of time preference equal to 4 and 8 percent, respectively. See the text for a description of the other parameter assumptions. 
Figure 1: Regression Adjusted Disability Prevalence by Age

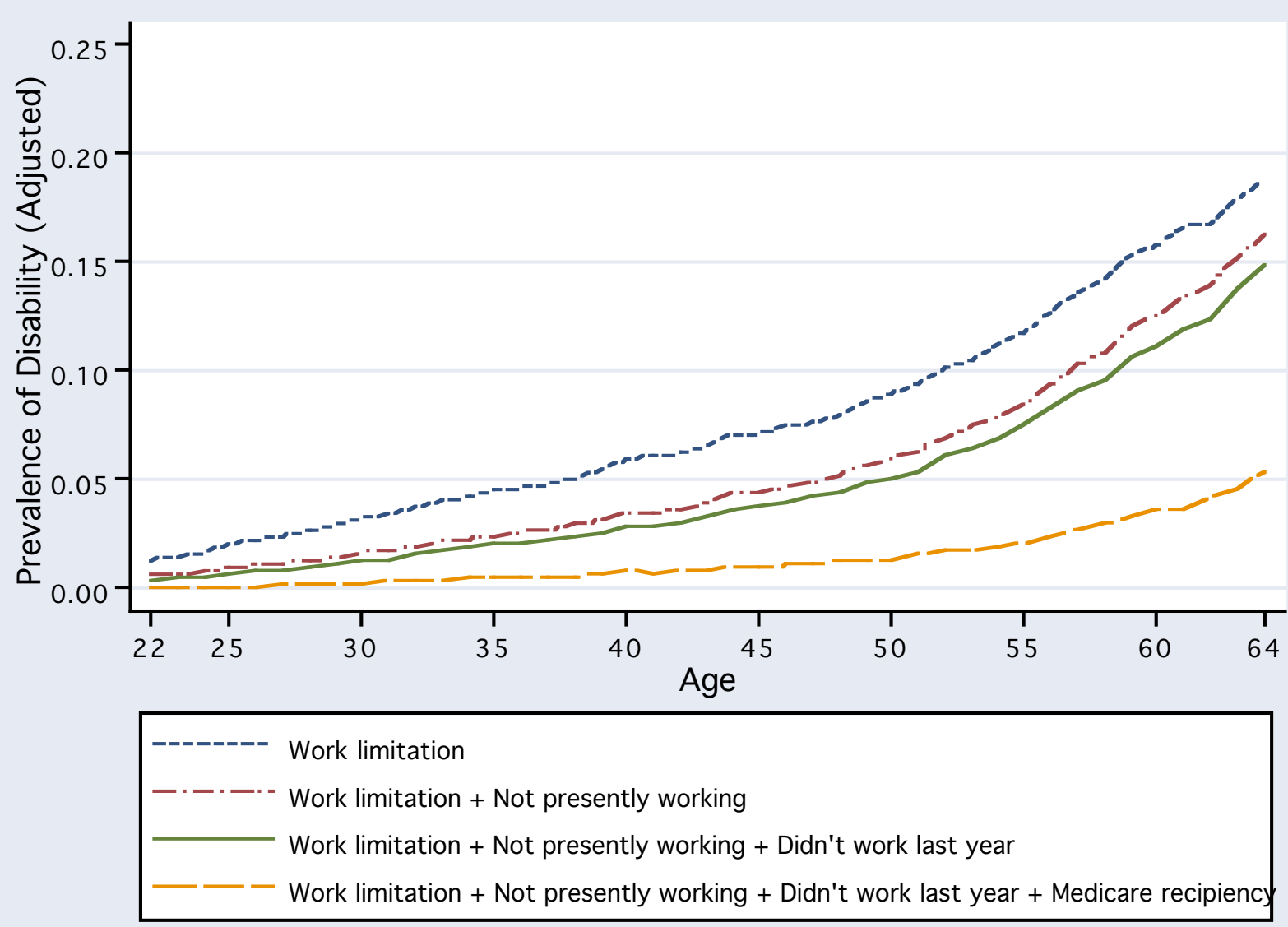

Figures report predicted probability of work-limiting disability using alternative definitions from a logistic regression that controls for an unrestricted set of age and year indicator variables, gender, race and ethnicity (four categories), education (two categories), marital status (three categories), marital status and gender interactions, census region (nine categories), metropolitan status, census division and metropolitan status interactions, the number of children under the age of eighteen in the family, and the size of the household. The above figure adjusts for all these covariates, except for age. The regression used CPS data from the 1980-2004 files of Annual Demographic Survey $(n=2,166,178)$. 
Figure 2: Regression Adjusted Disability Prevalence by Age over Time

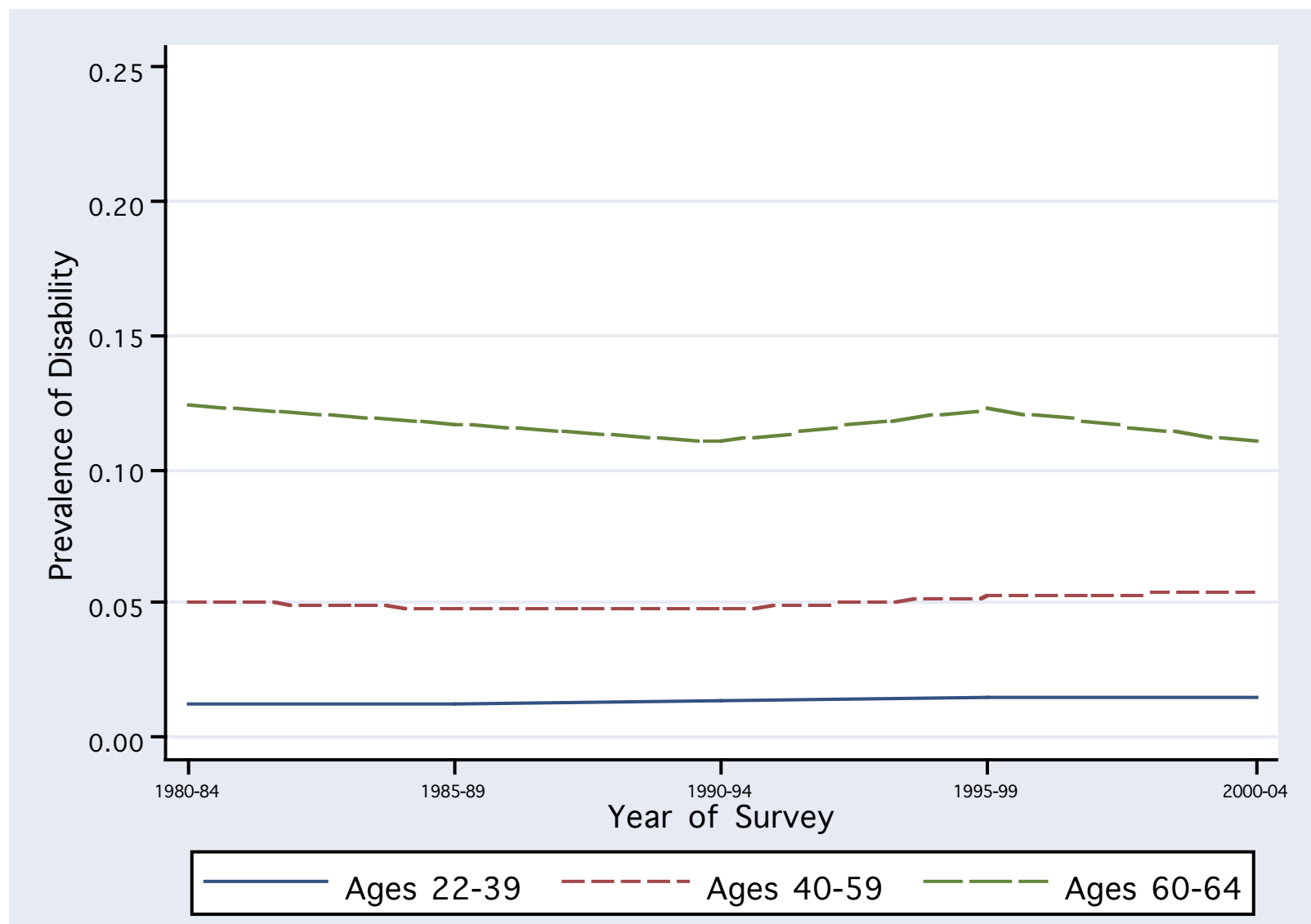

Figure report predicted probability of work-limiting disability from a logistic regression that controls for an unrestricted set of age and year indicator variables, gender, race and ethnicity (four categories), education (two categories), marital status (three categories), marital status and gender interactions, census region (nine categories), metropolitan status, census division and metropolitan status interactions, the number of children under the age of eighteen in the family, and the size of the household. The above figure adjusts for these covariates, except the ones used in the figure. The regression used CPS data from the 1980-2004 files of Annual Demographic Survey $(\mathrm{n}=2,166,178)$. 
Figure 3: Regression Adjusted Disability Prevalence by Gender over Time

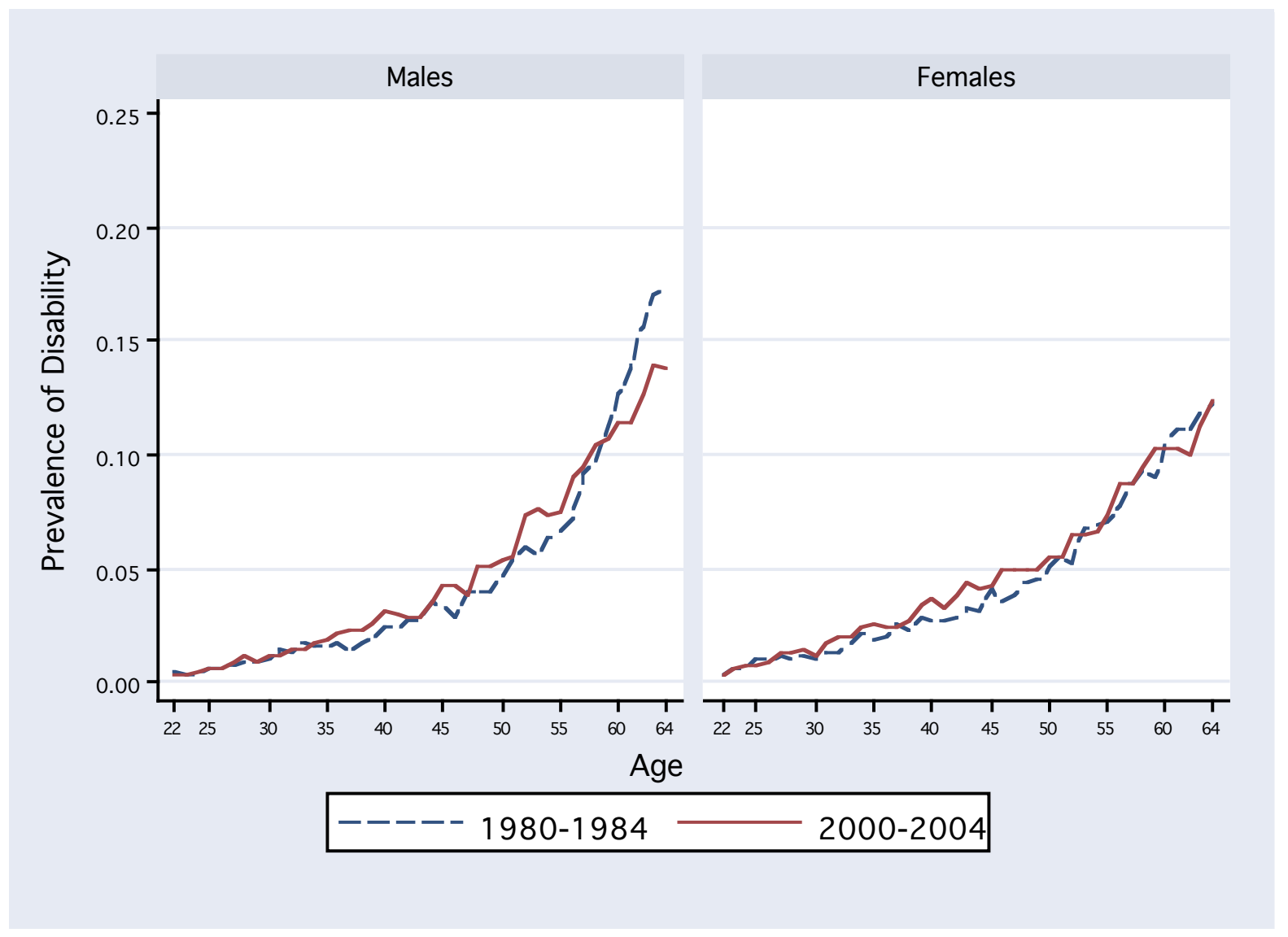

Figure report predicted probability of work-limiting disability from a logistic regression that controls for an unrestricted set of age and year indicator variables, gender, race and ethnicity (four categories), education (two categories), marital status (three categories), marital status and gender interactions, census region (nine categories), metropolitan status, census division and metropolitan status interactions, the number of children under the age of eighteen in the family, and the size of the household. The above figure adjusts for these covariates, except the ones used in the figure. The regression used CPS data from the 1980-2004 files of Annual Demographic Survey $(n=2,166,178)$. 
Figure 4: Regression Adjusted Disability Prevalence by Education over Time

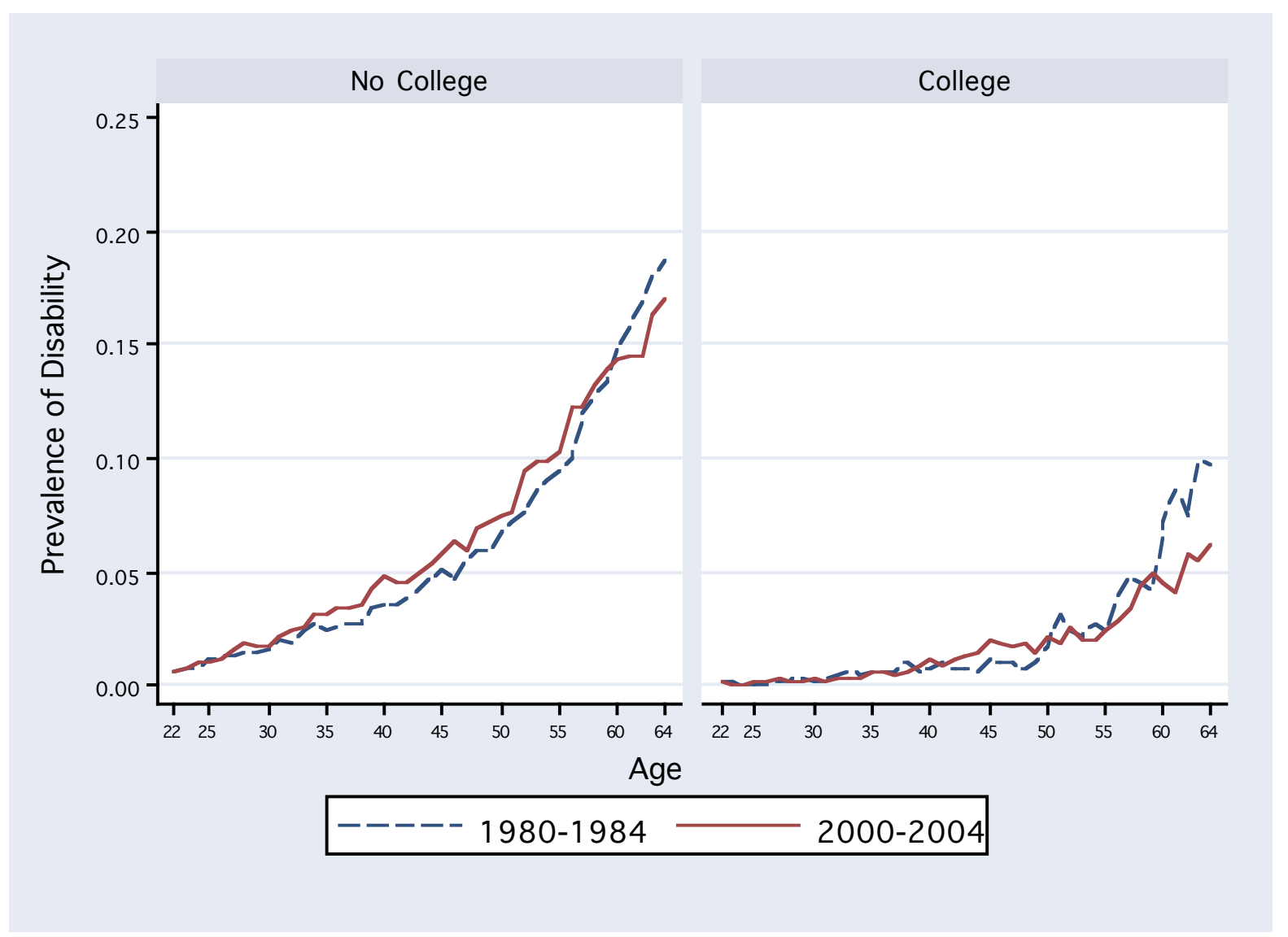

Figure report predicted probability of work-limiting disability from a logistic regression that controls for an unrestricted set of age and year indicator variables, gender, race and ethnicity (four categories), education (two categories), marital status (three categories), marital status and gender interactions, census region (nine categories), metropolitan status, census division and metropolitan status interactions, the number of children under the age of eighteen in the family, and the size of the household. The above figure adjusts for these covariates, except the ones used in the figure. The regression used CPS data from the 1980-2004 files of Annual Demographic Survey $(n=2,166,178)$. 
Figure 5: Regression Adjusted Disability Prevalence by Race over Time

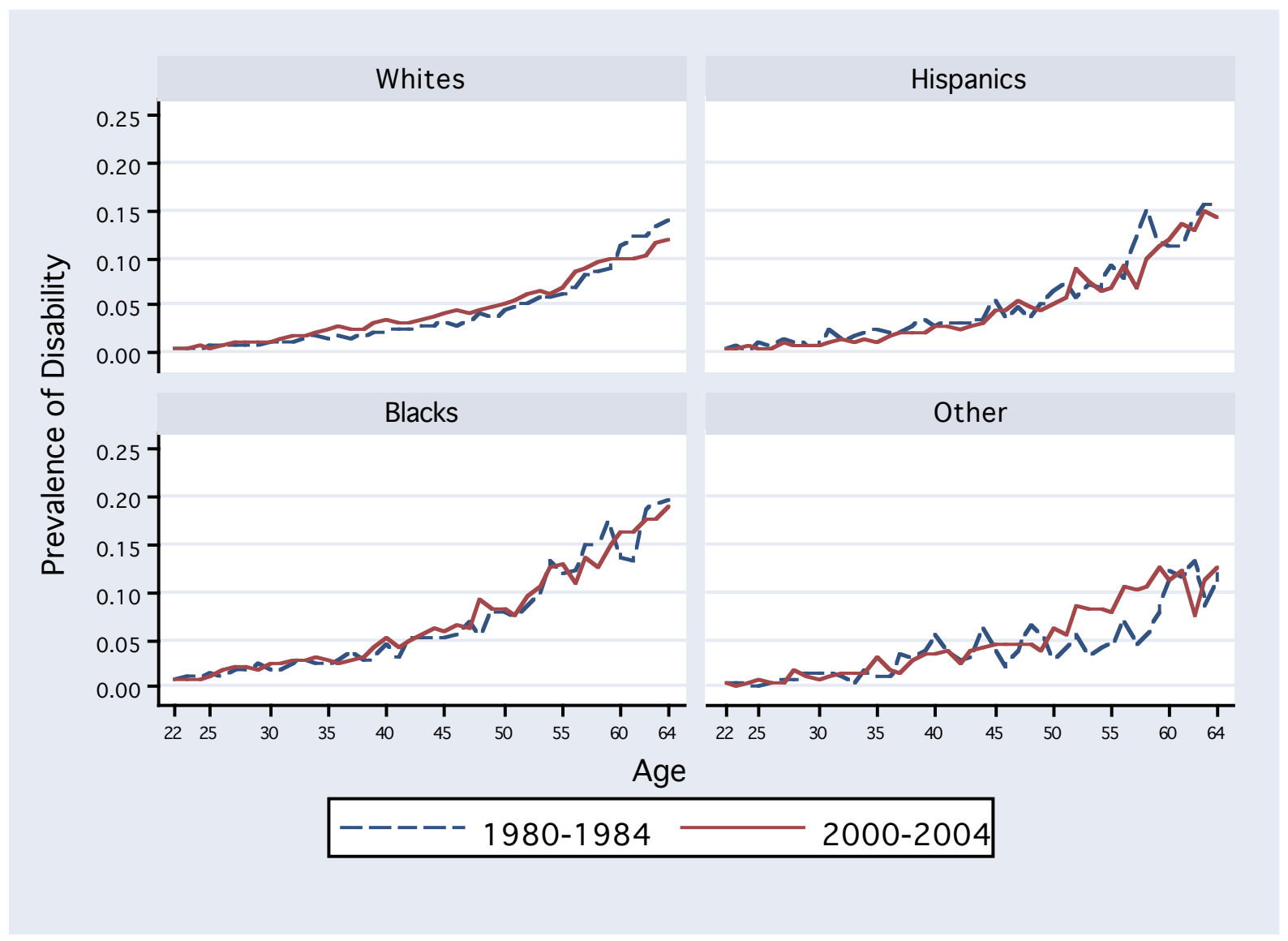

Figure report predicted probability of work-limiting disability from a logistic regression that controls for an unrestricted set of age and year indicator variables, gender, race and ethnicity (four categories), education (two categories), marital status (three categories), marital status and gender interactions, census region (nine categories), metropolitan status, census division and metropolitan status interactions, the number of children under the age of eighteen in the family, and the size of the household. The above figure adjusts for these covariates, except the ones used in the figure. The regression used CPS data from the 1980-2004 files of Annual Demographic Survey $(\mathrm{n}=2,166,178)$. 
Figure 6: Age-Consumption Profiles for Consumers Who Do Not Become Disabled
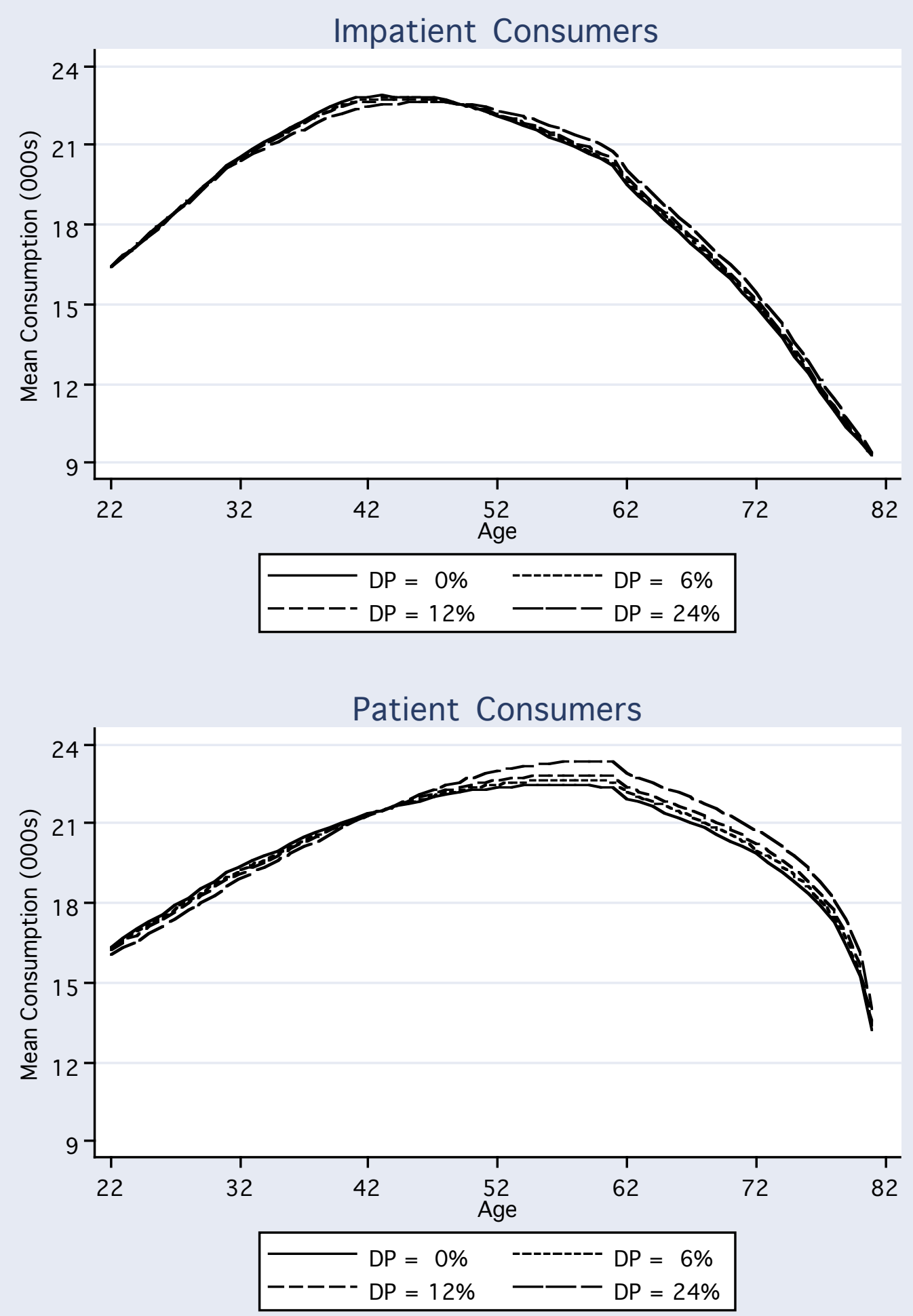
Figure 7: Age-Asset Profiles by Age of Disability
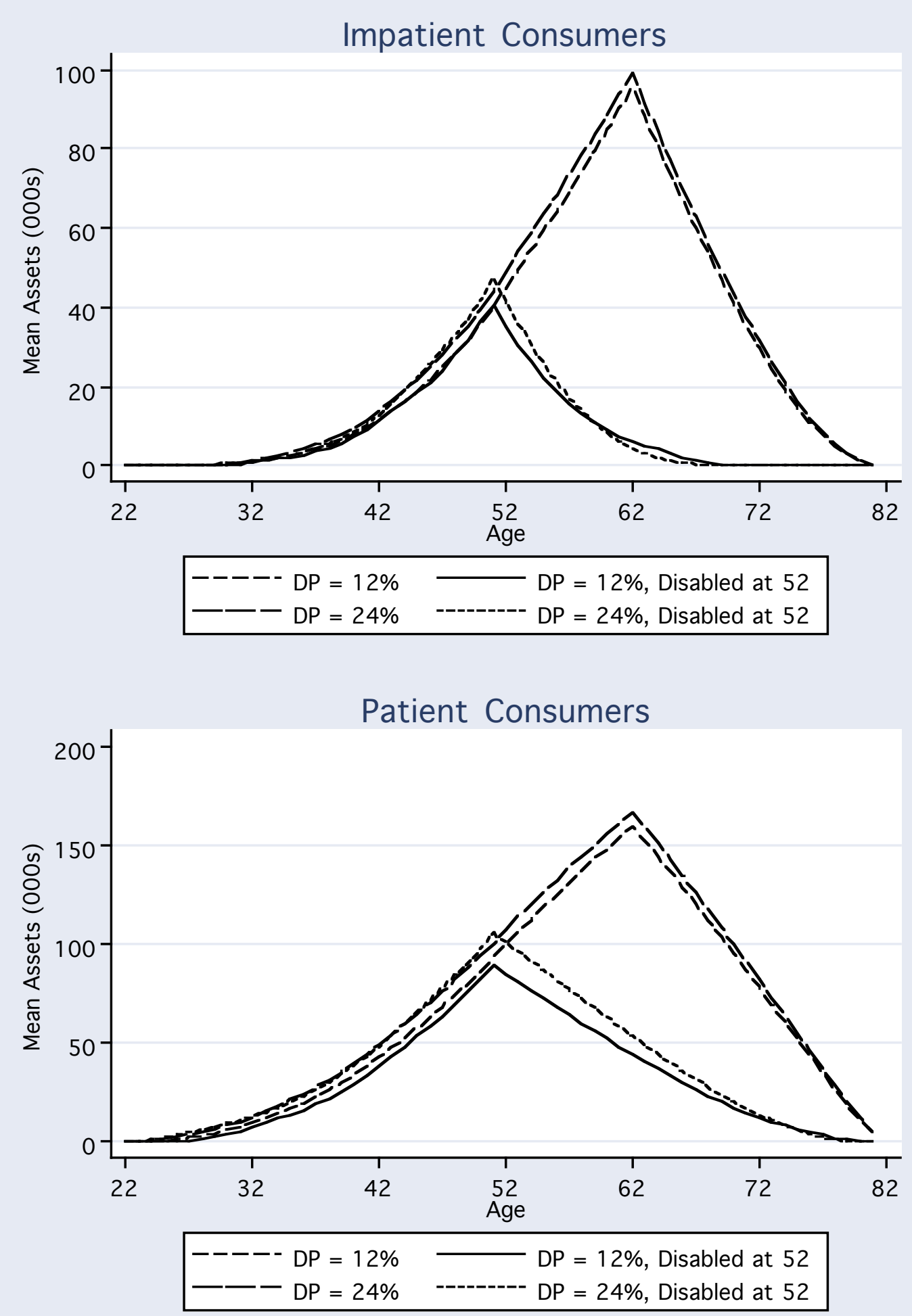
Figure 8: Age-Asset Profiles for Consumers Who Do Not Become Disabled
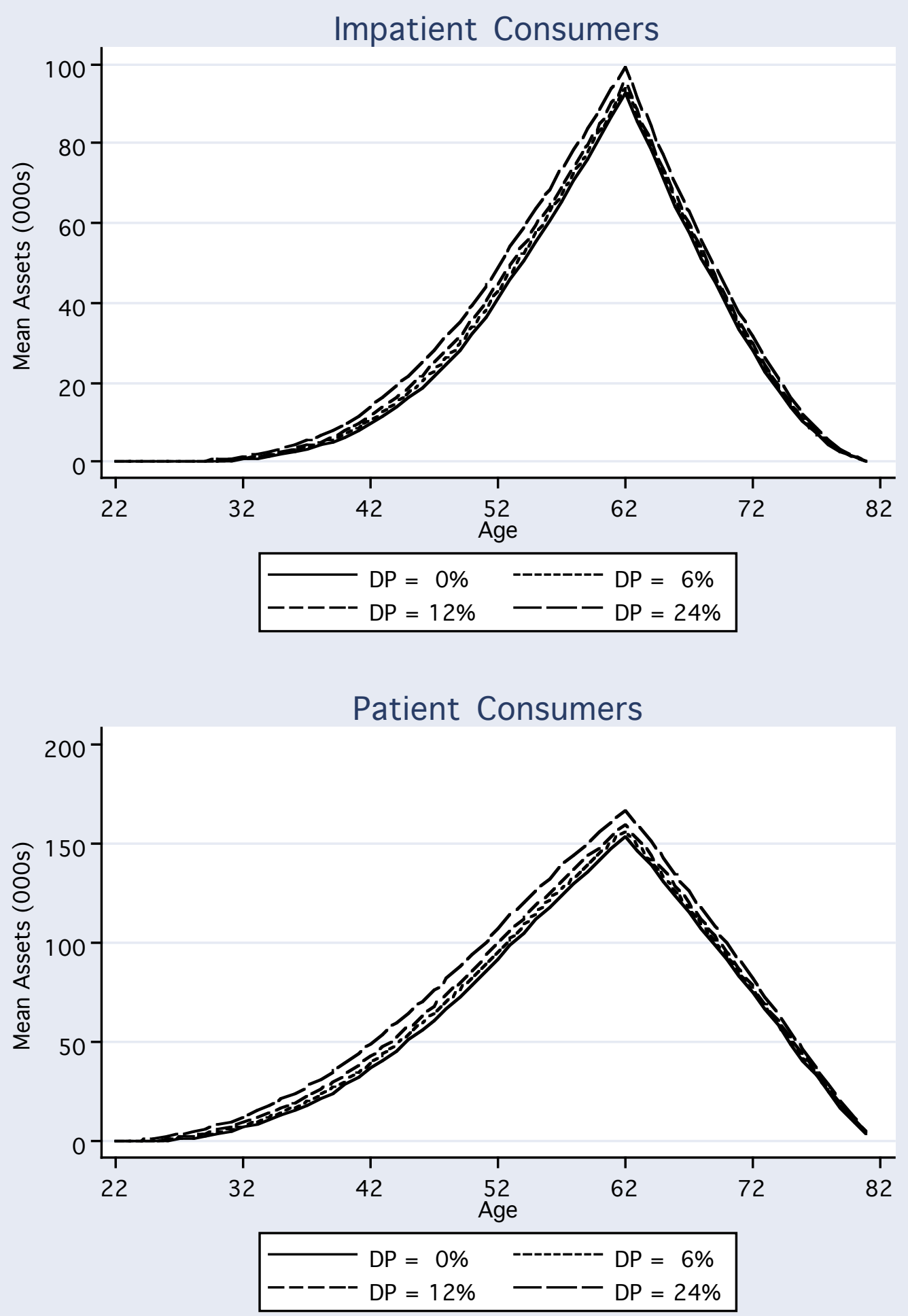
Figure 9: Age-Asset Profiles for Alternative Parameterizations for Consumers Who Do Not Become Disabled

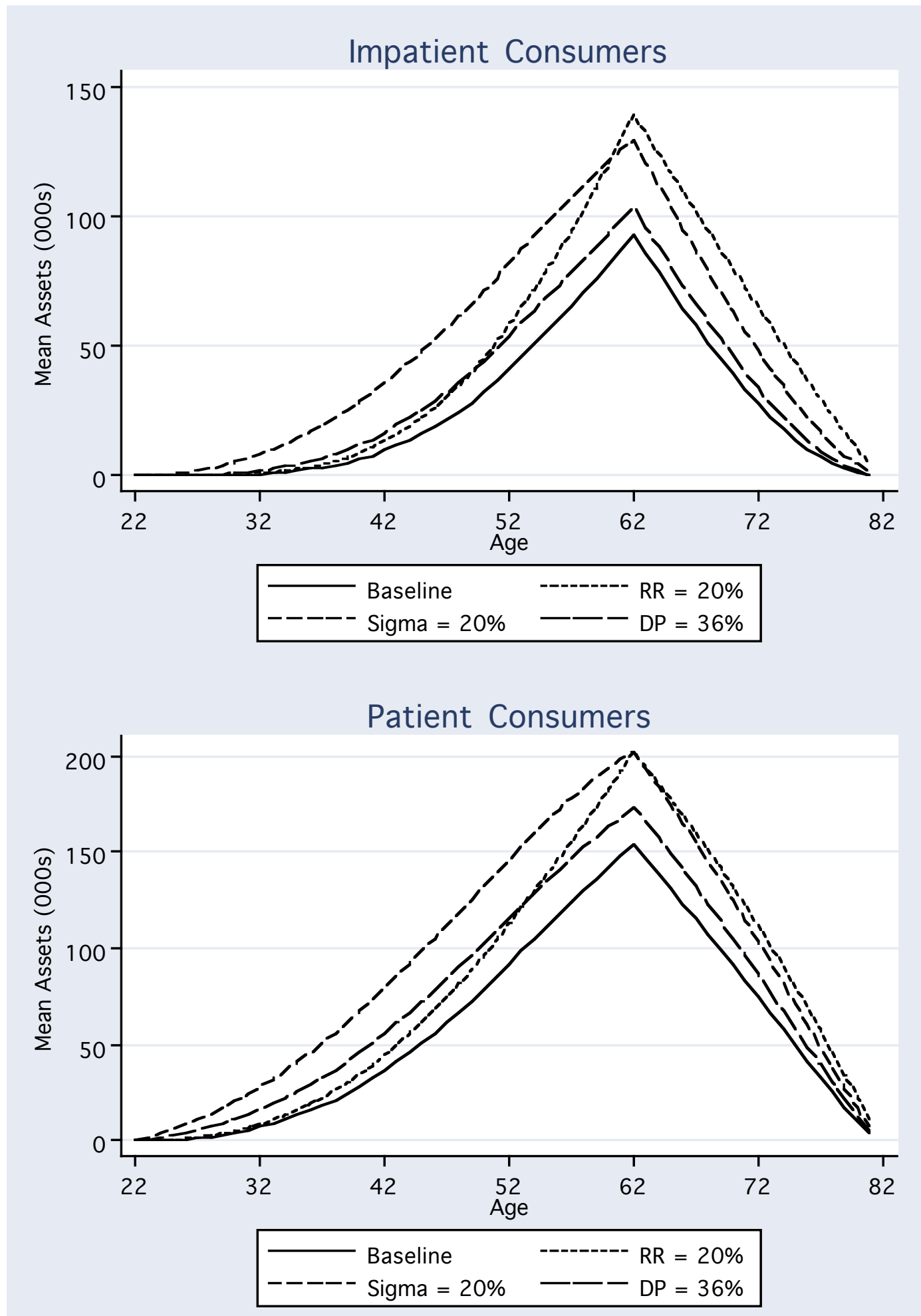


Figure A1: Regression Adjusted Disability Prevalence by Marital Status over Time

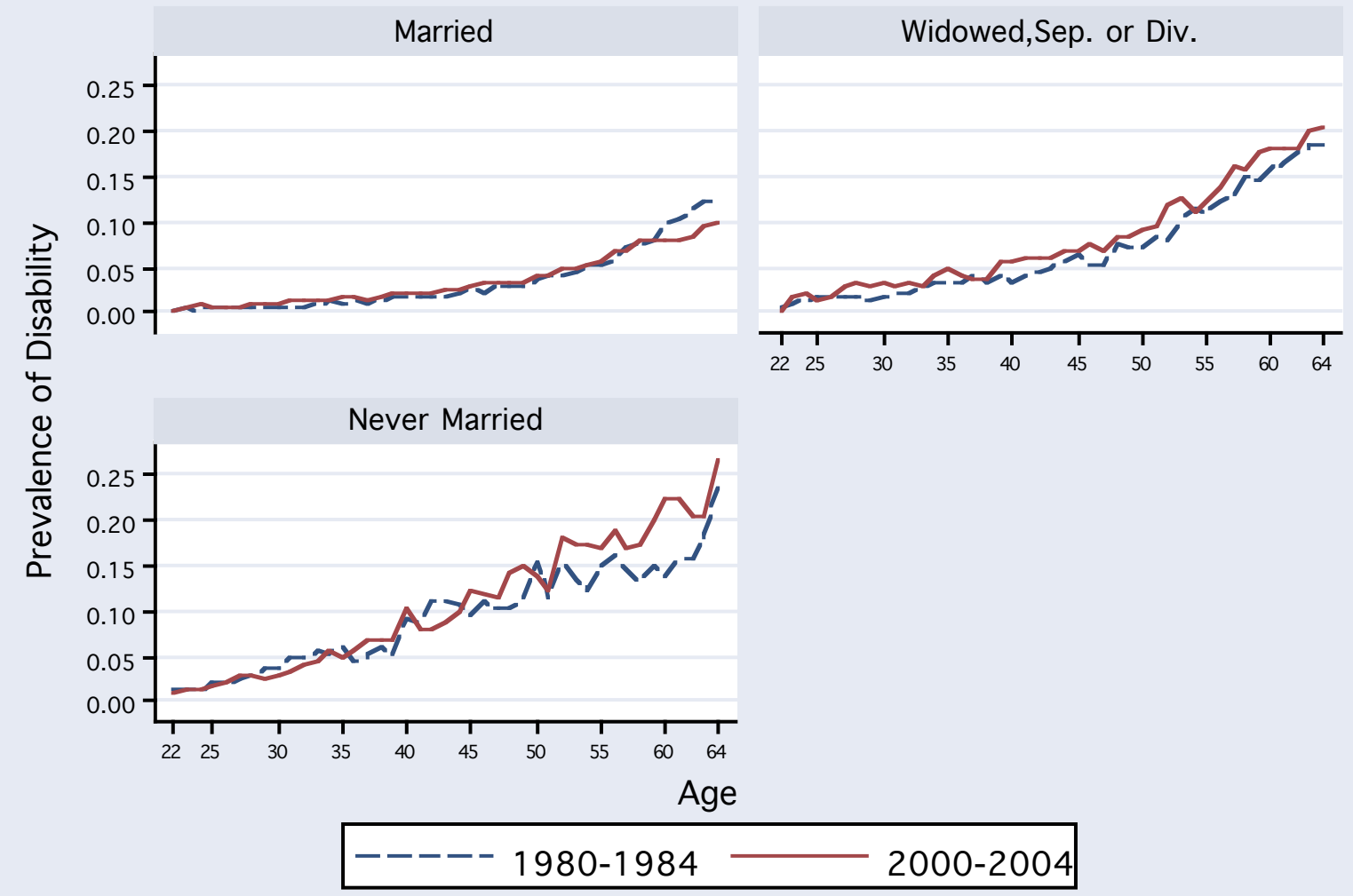

Figure report predicted probability of work-limiting disability from a logistic regression that controls for an unrestricted set of age and year indicator variables, gender, race and ethnicity (four categories), education (two categories), marital status (three categories), marital status and gender interactions, census region (nine categories), metropolitan status, census division and metropolitan status interactions, the number of children under the age of eighteen in the family, and the size of the household. The above figure adjusts for these covariates, except the ones used in the figure. The regression used CPS data from the 1980-2004 files of Annual Demographic Survey $(\mathrm{n}=2,166,178)$. 
Figure A2: Regression Adjusted Disability Prevalence by Marital Status and Gender

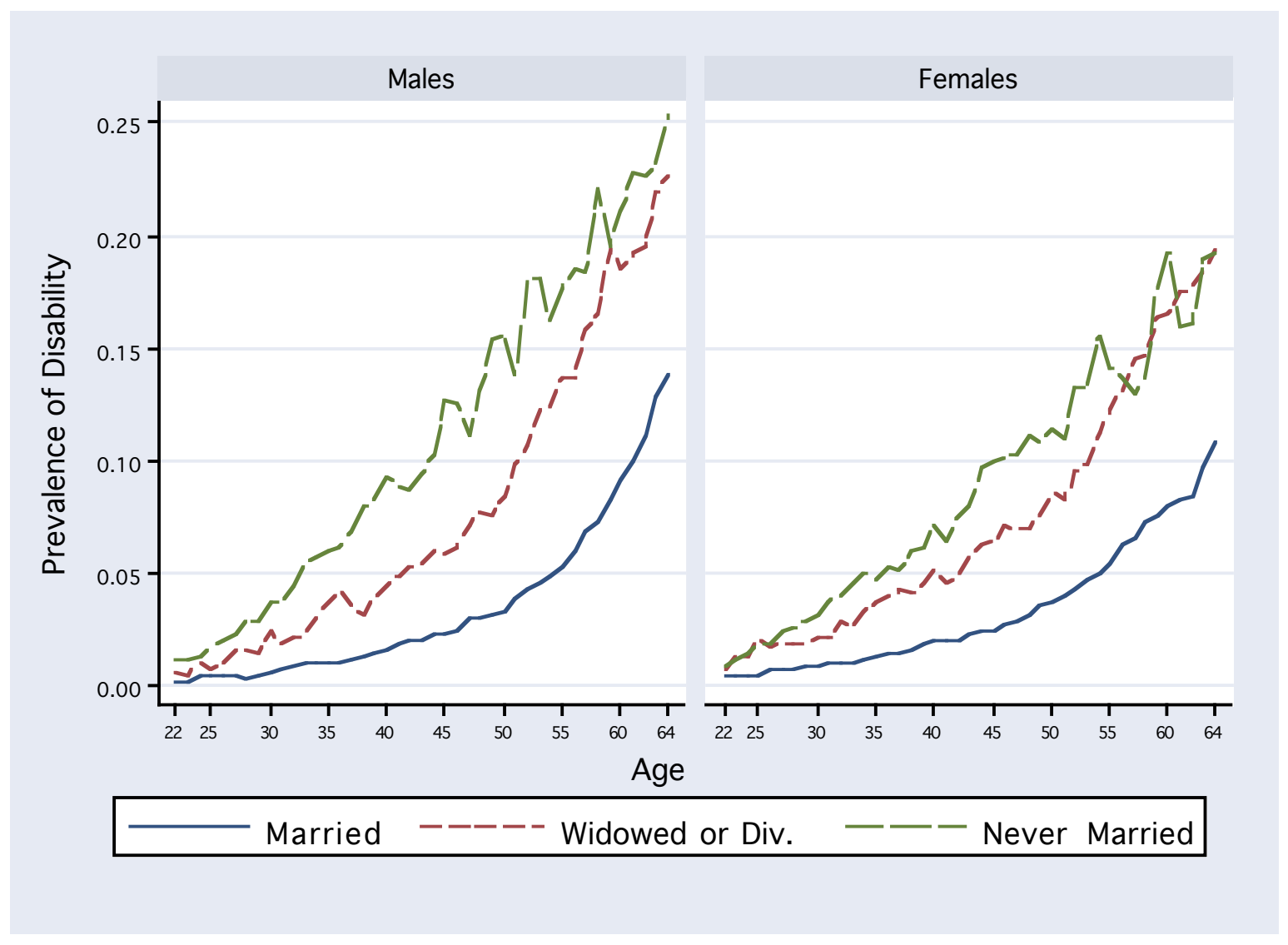

Figure report predicted probability of work-limiting disability from a logistic regression that controls for an unrestricted set of age and year indicator variables, gender, race and ethnicity (four categories), education (two categories), marital status (three categories), marital status and gender interactions, census region (nine categories), metropolitan status, census division and metropolitan status interactions, the number of children under the age of eighteen in the family, and the size of the household. The above figure adjusts for these covariates, except the ones used in the figure. The regression used CPS data from the 1980-2004 files of Annual Demographic Survey $(\mathrm{n}=2,166,178)$. 
Figure A3: Regression Adjusted Disability Prevalence by Education and Gender

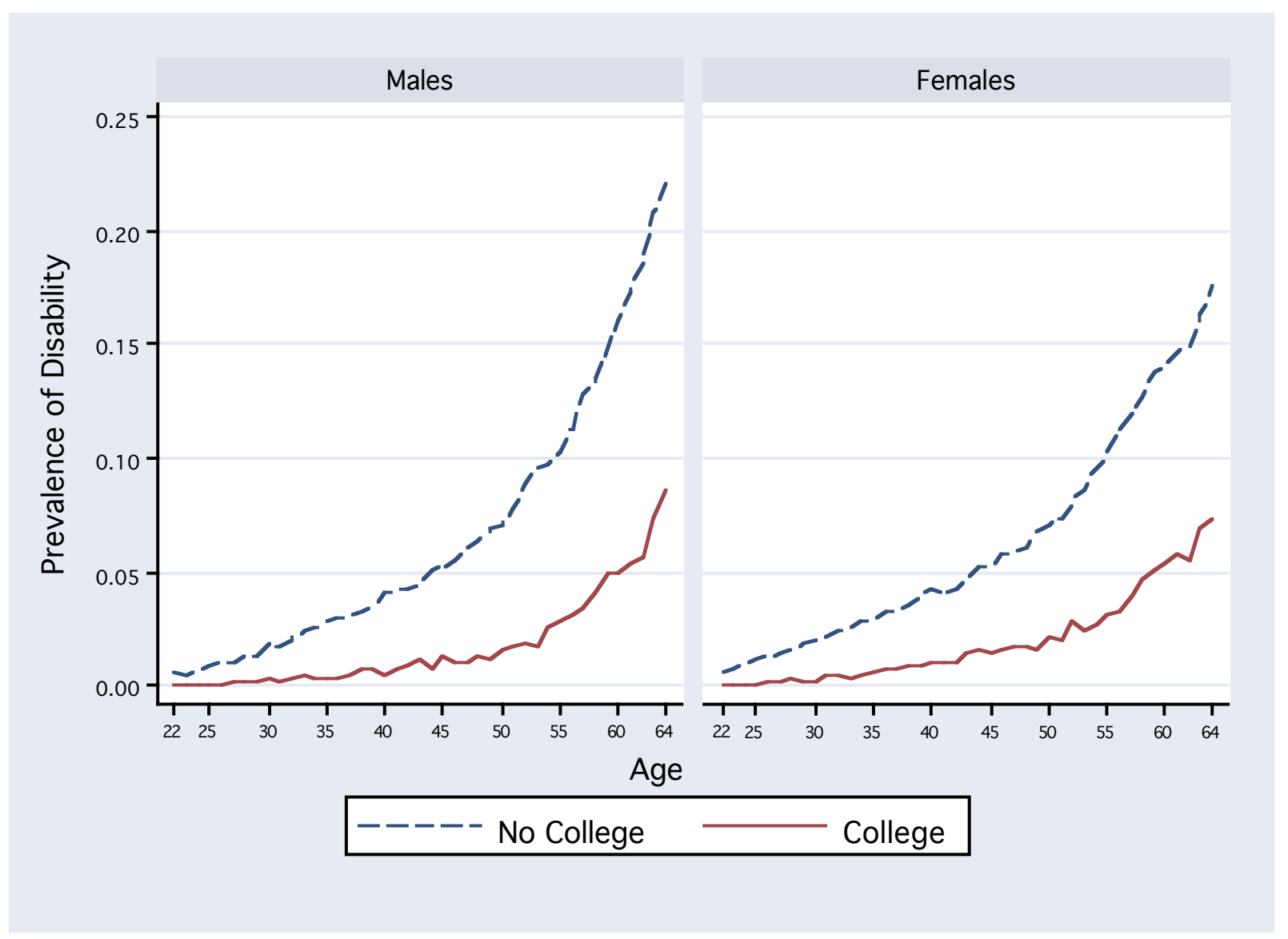

Figure report predicted probability of work-limiting disability from a logistic regression that controls for an unrestricted set of age and year indicator variables, gender, race and ethnicity (four categories), education (two categories), marital status (three categories), marital status and gender interactions, census region (nine categories), metropolitan status, census division and metropolitan status interactions, the number of children under the age of eighteen in the family, and the size of the household. The above figure adjusts for these covariates, except the ones used in the figure. The regression used CPS data from the 1980-2004 files of Annual Demographic Survey $(\mathrm{n}=2,166,178)$. 
Figure A4: Regression Adjusted Disability Prevalence by Metropolitan Status

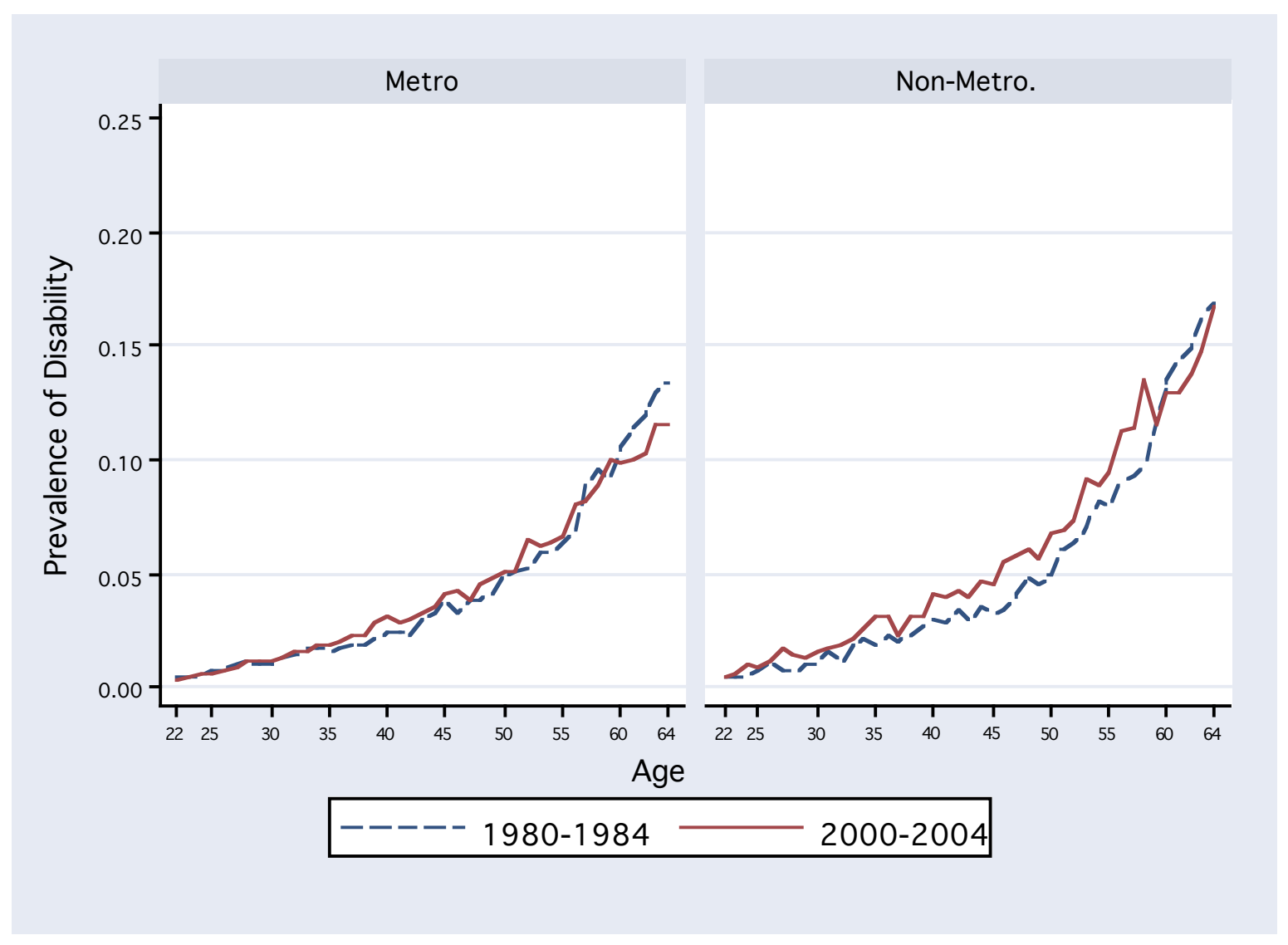

Figure report predicted probability of work-limiting disability from a logistic regression that controls for an unrestricted set of age and year indicator variables, gender, race and ethnicity (four categories), education (two categories), marital status (three categories), marital status and gender interactions, census region (nine categories), metropolitan status, census division and metropolitan status interactions, the number of children under the age of eighteen in the family, and the size of the household. The above figure adjusts for these covariates, except the ones used in the figure. The regression used CPS data from the 1980-2004 files of Annual Demographic Survey $(\mathrm{n}=2,166,178)$. 